LA W REN CE LIVERM ORE NATIONAL LABORATORY

Joining of Beryllium

Alfed Goldberg

September 26, 2006 
This document was prepared as an account of work sponsored by an agency of the United States Government. Neither the United States Government nor the University of California nor any of their employees, makes any warranty, express or implied, or assumes any legal liability or responsibility for the accuracy, completeness, or usefulness of any information, apparatus, product, or process disclosed, or represents that its use would not infringe privately owned rights. Reference herein to any specific commercial product, process, or service by trade name, trademark, manufacturer, or otherwise, does not necessarily constitute or imply its endorsement, recommendation, or favoring by the United States Government or the University of California. The views and opinions of authors expressed herein do not necessarily state or reflect those of the United States Government or the University of California, and shall not be used for advertising or product endorsement purposes.

This work was performed under the auspices of the U.S. Department of Energy by University of California, Lawrence Livermore National Laboratory under Contract W-7405-Eng-48. 
DTED Report No: CODTU-2004-1513

\title{
JOINING OF BERYLLIUM
}

\author{
Alfred Goldberg \\ One of a Series of Reports on Beryllium
}

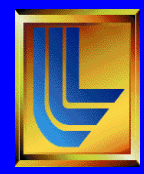

May 15, 2004

Lawrence Livermore National Laboratory, Livermore, CA 94551

This effort is funded by the Weapons System Engineering

Certification Campaign (C6) 


\title{
JOINING OF BERYLLIUM
}

\author{
Alfred Goldberg \\ TABLE OF C ONTENTS
}

Introduction.

Page

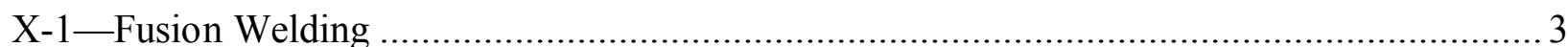

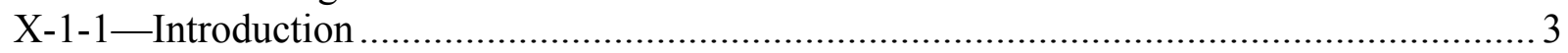

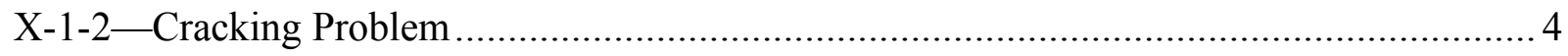

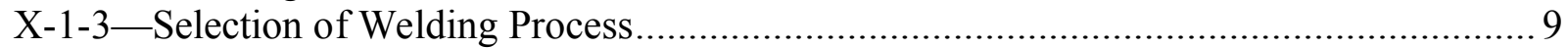

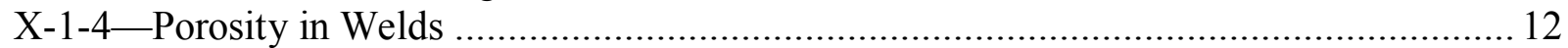

X-1-5-Surface Preparation............................................................................... 13

X-1-6_Filler Metals and Feed Rates.................................................................... 14

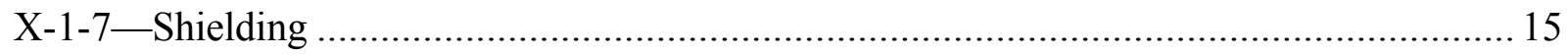

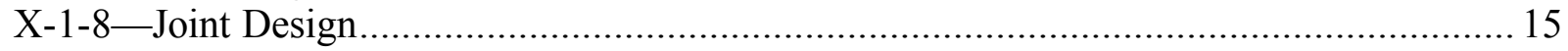

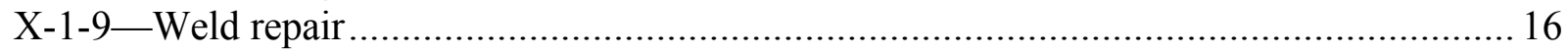

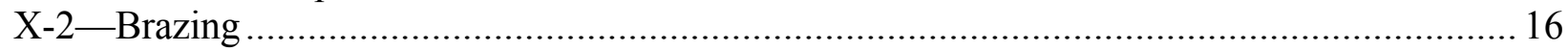

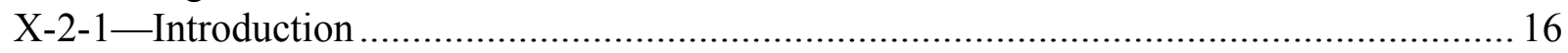

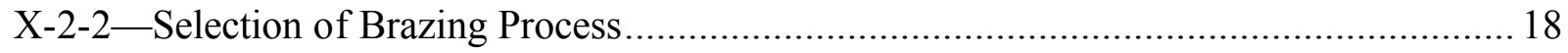

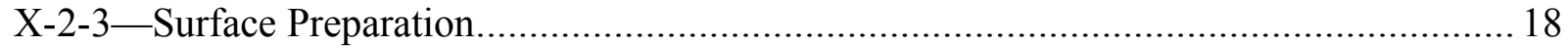

X-2-4_Filler Metals .......................................................................................... 19

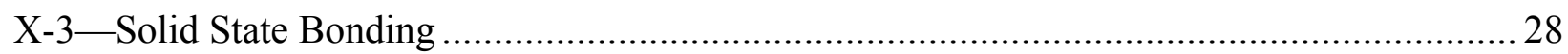

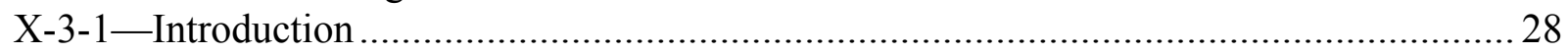

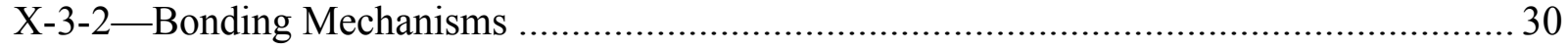

X-3-3 - Intermediate Layers (Indirect Bonding) ................................................... 32

X-3-4-Surface Preparation.............................................................................. 35

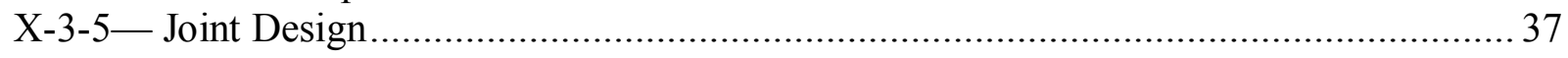

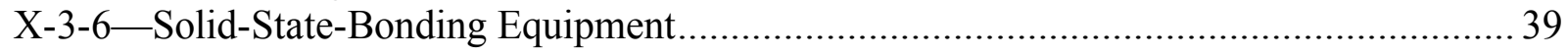

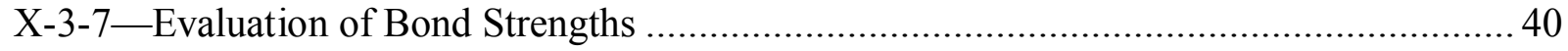

X-3-8 — Bonding of Beryllium with other Materials ..................................................... 40

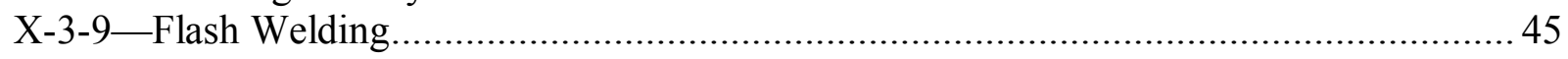

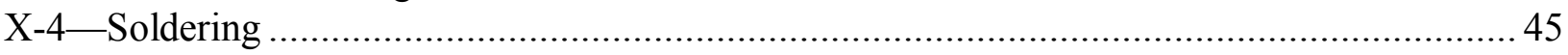

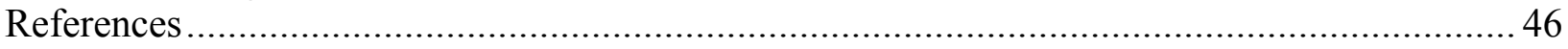




\section{Introduction}

A handbook dealing with the many aspects of beryllium that would be important for the users of this metal is currently being prepared. With an introduction on the applications, advantages and limitations in the use of this metal the following topics will be discussed in this handbook: physical, thermal, and nuclear properties; extraction from the ores; purification and casting of ingots; production and types of beryllium powders; consolidation methods, grades, and properties; mechanical properties with emphasis on the various factors affecting these properties; forming and mechanical working; welding, brazing, bonding, and fastening; machining; powder deposition; corrosion; health aspects; and examples of production of components. This report consists of "Section X-Joining" from the handbook. The prefix X is maintained here for the figures, tables and references. In this section the different methods used for joining beryllium and the advantages, disadvantages and limitations of each are presented. The methods discussed are fusion welding, brazing, solid state bonding(diffusion bonding and deformation bonding), soldering, and mechanical fastening. Since beryllium has a high affinity for oxygen and nitrogen with the formation of oxides and nitrides, considerable care must be taken on heating the metal, to protect it from the ambient atmosphere. In addition, mating surfaces must be cleaned and joints must be designed to minimize residual stresses as well as locations for stress concentration (notch effects).

In joining any two metals the danger exists of having galvanic corrosion if the part is subjected to moisture or to any type of corroding environment. This becomes a problem if the less noble (anodic) metal has a significantly smaller area than the more noble (cathodic) metal since the ions (positive charges) from the anodic (corroding) metal must correspond to the number of electrons

(negative charges) involved at the cathode. Beryllium is anodic to almost all metals ${ }^{1}$; thus, when joined to other metals and exposed even to a mild environment it may be susceptible to corrosion. In designing a Be-metal joint one must also consider the environment to which the assembled component will be exposed in service.

\section{X-1-Fusion Welding}

\section{$\underline{\mathrm{X}-1-1-\text { Introduction }}$}

Beryllium has a high affinity for oxygen, forming stable oxides, and cannot be fusion-welded by any process that utilizes fluxes or where heated metal is exposed to the atmosphere. Beryllium also reacts with atmospheric nitrogen, forming nitrides at the surface. Both the strongly adherent oxide film and the nitrided surface inhibit wetting, flow, and coalescence during welding or brazing.

The most common problems associated with fusion welding beryllium are the susceptibility to cracking and control of grain size in the weld metal and in the heat-affected zone (HAZ). Three types of cracking commonly occur: hot cracking, cracking originating at defects, and cracking due to thermally induced stresses. Hot cracking is primarily due to a low melting-point aluminumrich, grain-boundary film, the aluminum being an impurity in the beryllium. 


\section{$\underline{\mathrm{X}-1-2-\text { Cracking Problem }}$}

In fusion welding, a cast microstructure with relatively large-oriented grains forms in the fusion zone and, to some degree, in the HAZ. A low effective heat input ${ }^{\mathrm{a}}$ will minimize the grain size as well as provide a narrow HAZ. High travel speeds are to be avoided as the elongation of the weld pool increases with an increase in travel speed. Elongated weld pools tend to cause grain growth to stop abruptly at the centerline of the weld with little change in grain orientation, producing a boundary-like structure as illustrated in Fig. X-1-1. Such welds have been found to have the poorest resistance to cracking. Thus, moderate travel speeds, which should provide an optimum compromise between heat input and microstructure, may be best. ${ }^{2}$

The high thermal conductivity of beryllium, which results in a relative low thermal gradient, increases the difficulty of maintaining a narrow HAZ. With the eutectic liquid being essentially aluminum (see Fig. X-1-2), and being the final liquid to solidify, a high concentration of aluminum may form along the grain boundaries. The combination of coarse cast grains with aluminum-rich grain boundaries accentuates the hot-cracking problem. The tendency for hot cracking can be reduced by control of the aluminum content and the $\mathrm{Al} / \mathrm{Fe}$ ratio; the optimum ratio is about $2.4 .^{3}$ The range of iron and aluminum contents to produce good welds is illustrated in Fig. X-1-3. Figure X-1-4 contains a bar graph showing the effect of impurity content of a number of impurities on the susceptibility to weld cracking in beryllium. ${ }^{2}$
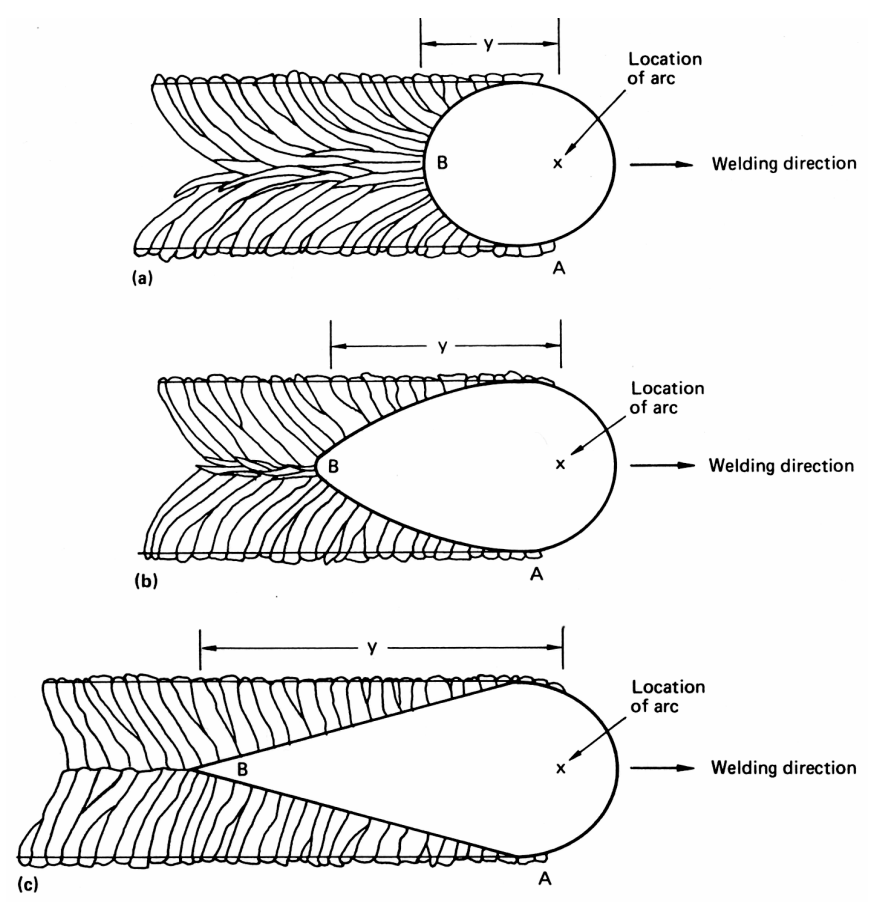

Fig. X-1-1 Comparison of weld-pool shapes. Travel speeds: (a) slow, (b) intermediate, (c) fast. ${ }^{4}$

\footnotetext{
${ }^{\mathrm{a}}$ Heat input $($ joules $/$ meter $)=[($ current $\mathrm{x}$ voltage $) /($ welding speed $)]$; current $\mathrm{x}$ voltage is in joules/second, speed is in meters/second
} 
As seen in Fig. X-1-1, the grain macrostructure is influenced by the welding speed. Although increasing the speed decreases the heat input, the resulting elongated weld pool caused the solidification and growth of the grains to proceed more in a direction normal to the weld centerline. Thus, the grain growth from either side of the centerline stops abruptly at the centerline producing there a boundary-like structure. Such welds have been found to be the least resistant to cracking.

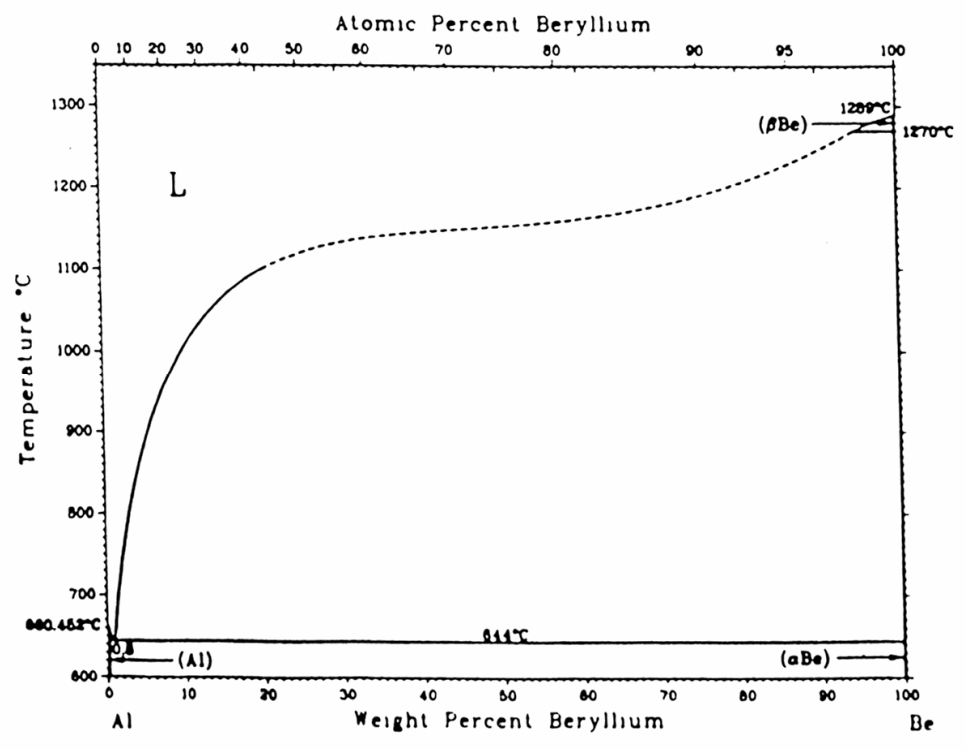

Fig. X-1-2 Aluminum-beryllium phase diagram. ${ }^{5}$

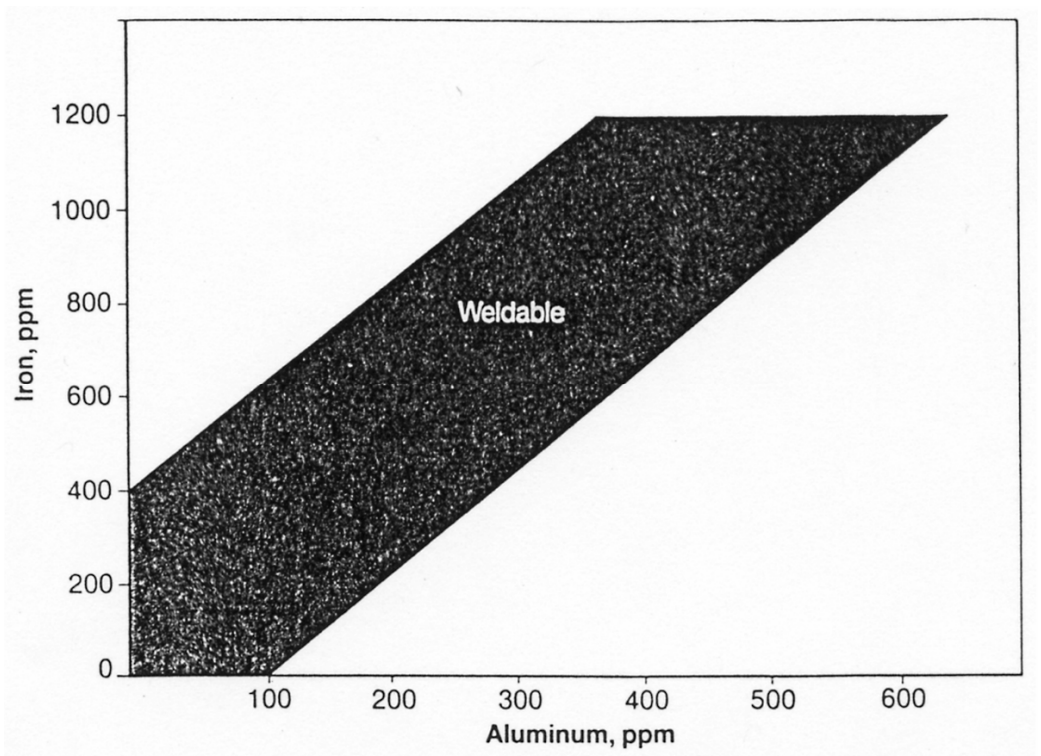

Fig. X-1-3 Range of iron and aluminum contents in beryllium to produce good welds. ${ }^{7}$ 
Cracking can originate at defects such as oxide particles, inclusions, voids, and surface markings. Machining defects, including deformation-induced twins, may also act as crack-nucleation sites. Thus, it is best to remove a $0.10-\mathrm{mm}$ layer of the machined surface before welding, and this is usually done by etching. ${ }^{2}$ An increase in oxide content in the base metal was found to increase the occurrence of both undercutting and porosity. These defects are the result of the formation of an oxide film on the surface of the weld pool. This film interferes with the welding process by increasing the turbulence in the weld pool, which, in turn, mixes the oxide into the solidifying weld. The turbulence also causes an increase in weld-surface roughness. ${ }^{3}$

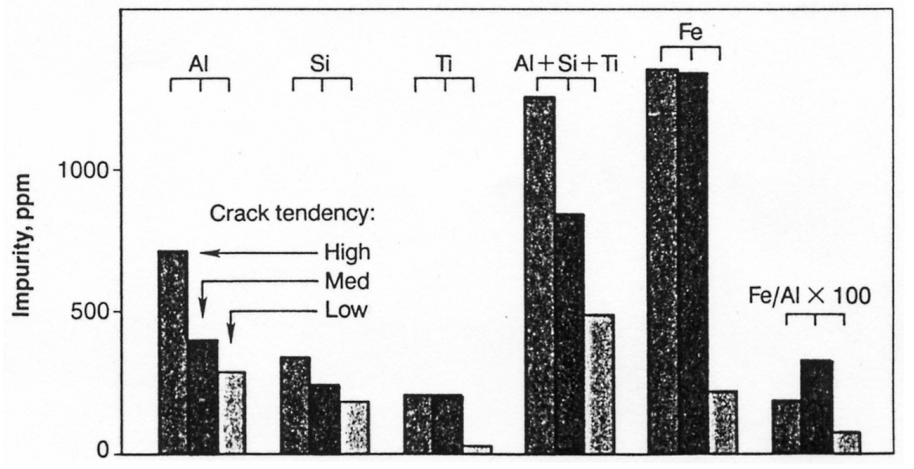

Fig.X-1-4 Crack tendency of beryllium relative to its impurity content. ${ }^{2}$

Cracking can also result from the inherently brittle beryllium not being able to accommodate the thermally induced stresses. High tensile stresses can be generated perpendicular to the weld along the weld centerline where the microstructure is most susceptible to cracking. Thermally induced stresses are related to the high cooling rates and temperature gradients developed during welding. Both types of stresses can be reduced by preheating ${ }^{b}$ the parts at some intermediate temperature for a period of time to allow transfer of heat throughout the parts prior to being joined. Preheating also increases the ductility, so that the thermally-induced stresses are relieved by plastic flow rather than by cracking. Crack-free, full-penetration welds have been achieved in ingot-sheet beryllium up to $1.52 \mathrm{~mm}$ thick using a preheat of $400^{\circ} \mathrm{C}$. Beryllium made from low-oxide powder $(0.5 \% \mathrm{BeO})$ has been successfully welded in thicknesses up to $2.5 \mathrm{~mm}$ with preheats of $340^{\circ} \mathrm{C}$. In general, preheats should be used for autogeneous ${ }^{c}$ welding of beryllium in sections thicker than approximately $2 \mathrm{~mm}$. ${ }^{6}$. A $2.54-\mathrm{mm}$-thick product, made from powder having an oxide content of $0.5 \%$, was successfully welded following a preheat at $340^{\circ} \mathrm{C}$. If weld cracking cannot be avoided with autogenous welding, adding an $\mathrm{Al}-12 \% \mathrm{Si}$ filler alloy may help by creating an aluminumrich, low-melting-temperature fusion zone with the liquid being available to backfill cracks. Enrichment with aluminum, however, reduces the weld strength and lowers the service temperature of the beryllium.

Porosity, weld undercutting, and related cracking can be reduced by decreasing the oxide content of the base metal. The maximum permissible $\mathrm{BeO}$ content for single-pass, full-penetration welds

\footnotetext{
${ }^{\mathrm{b}}$ Preheating refers to heating up a part to a predetermined uniform temperature prior to welding

${ }^{\mathrm{c}}$ An autogeneous weld is a fusion weld made without the addition of a filler metal.
} 
in beryllium decreases with increasing thickness of the base metal. This is due to the increase in weld-pool agitation and the more severe stress gradients associated with the increased heat inputs required with thicker materials. Successful single-pass, electron-beam welds have been made with 1.6-mm and 3.2-mm-thick beryllium parts containing 1.7 to $1.84 \mathrm{wt} . \% \mathrm{BeO}^{2,3}$

An investigation evaluated the source of centerline cracking in autogenous beryllium weldments. ${ }^{8}$ Centerline fusion-zone cracks were generated in rolled ingot-grade-beryllium plates, measuring $6.35 \mathrm{~mm}$ thick $\times 75 \mathrm{~mm} \times 25 \mathrm{~mm}$. The fusion zone was formed by electron-beam welding a bead along the center of the plate, which is unrestrained. Optical, transmission-electron, and scanning electron microscopy were performed on transverse and in-plane sections of the plate across and along the cracked weld. In addition, chemical analysis was performed. Typical of autogenous beryllium weldments, long columnar grains had formed, having nucleated epitaxially ${ }^{\mathrm{d}}$ on partially melted base-metal grains. The growth followed the direction of heat flow in the weld pool and was oriented nearly parallel to the welding direction at the centerline. The weld travel speed was between 2.5 and $4.2 \mathrm{~mm} /$ second with $100 \%$ penetration of the plate. The directional growth and the crack that had formed at the intersection of the two growth fronts along the centerline can be seen in Fig. X-1-5.

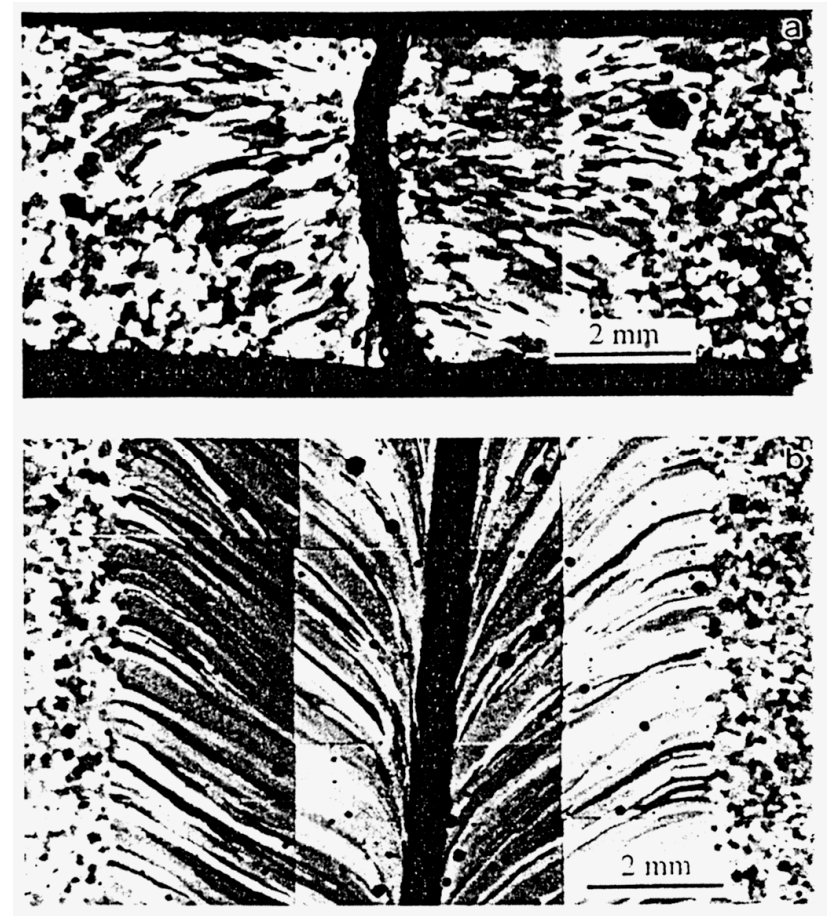

Fig. X-15 Light optical photographs of typical weld sections, as imaged by polarized light: a) transverse cross section, b) in-plane cross section. ${ }^{8}$

\footnotetext{
${ }^{\mathrm{d}}$ Epitaxial growth occurs when the crystallographic orientation of a deposited crystalline material follows the crystallographic orientation of the base material on which it nucleates.
} 
During solidification, impurities, following the direction of heat flow, are pushed toward the centerline and ultimately to the boundaries of the impinging dendrites ${ }^{\mathrm{e}}$ and the associated columnar grains. Thus, cracking was attributed to the formation along the columnar-grain boundaries of a film of $\mathrm{MBe}_{12}$ ( $\mathrm{M}$ refers to the metallic impurities in $\mathrm{Be}$ ) along with low-meltingpoint, three-phase particles consisting of elemental $\mathrm{Si}$, elemental $\mathrm{Al}$, and $\mathrm{AlFeBe}_{4}$ formed along the columnar-grain boundaries. Fracture characterization of the weld was obtained by extending an existing weld crack through the remaining intact (unaffected) metal and comparing it with the weld-crack surface. Whereas, the unaffected metal showed the characteristics of a typical brittle fracture, e. g. cleavage facets, these characteristics were absent in the weld fractures. The latter exhibited a taffy-like flow with width dimensions corresponding to those of the columnar grains, suggesting that the fracture is caused by the grain-boundary low-melting phases and, thus, is due to hot shortness ${ }^{f}$. The gross difference between the two fractures can be seen in Fig.X-1-6; the unaffected-metal fracture is seen in the lower left region of view (a). The taffy-like feature is shown in view (b).
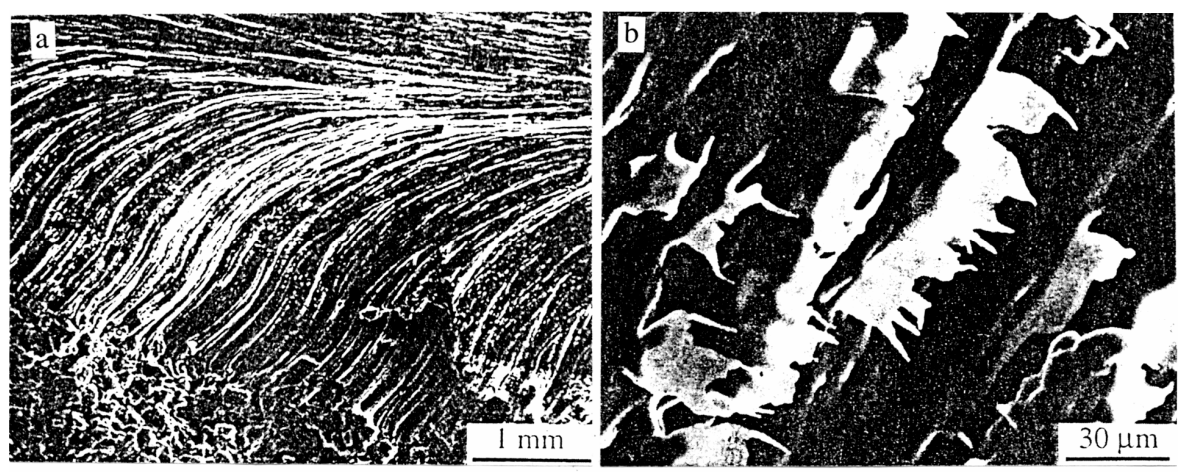

Fig. X-1-6 SEM micrographs of the weld fracture surface: a) low magnification showing overall structure, b) high magnification showing taffy-like features of centerline- weld crack. $^{8}$

Thermal stresses result from temperature gradients induced during welding. Preheating can reduce these stresses. The preheat also increases the ductility so that the stresses are relieved by plastic flow rather than by cracking. A preheat of $400^{\circ} \mathrm{C}$ allowed crack-free, full-penetration welds to be made in ingot sheet up to $1.52 \mathrm{~mm}$ thick. A 2.54-mm-thick product, made from powder having an oxide content of $0.5 \%$, was successfully welded following a preheat at $340^{\circ} \mathrm{C}^{2}$ In general, sections thicker than about $2 \mathrm{~mm}$ that are to be welded autogenously should be preheated. If weld cracking cannot be avoided with autogenous welding, adding an Al-12\% Si filler alloy may help by creating an aluminum-rich, low-melting-temperature fusion zone with the liquid being available to backfill cracks. Enrichment with aluminum, however, reduces the weld strength as well as lowering the service temperature of the beryllium.

\footnotetext{
${ }^{\mathrm{e}}$ The word dendrite is derived from the Greek word meaning "of a tree." The tree-like structure develops as solidification occurs by "spikes" or "branches" growing crystallographically into the liquid. The liquid in between the branches continually become enriched in those constituents that lower its melting temperature. The compositional gradients that develop as the liquid solidifies allows the dendritic structure to be revealed by etching. ${ }^{\mathrm{f}}$ Hot shortness refers to the inability of a material to be worked or deformed at an elevated temperature as a result of disintegrating or fracturing due to the presence of a low-melting, grain-boundary film
} 
Decreasing the oxide content of the base metal can reduce porosity, weld undercutting, and related cracking. The maximum permissible $\mathrm{BeO}$ content for single-pass, full-penetration welds in beryllium decreases with increasing thickness of the base metal. This is due to the increase in weld-pool agitation and the more severe stress gradients associated with the increased heat inputs required with thicker materials. Successful electron-beam welds have been made with1.6-mm and 3.2-mm-thick beryllium parts containing 1.7 to $1.84 \mathrm{wt} . \% \mathrm{BeO}^{3}$

\section{$\underline{X-1-3-\text { Selection of Welding Process }}$}

Various grades of beryllium are made with different powder sources, consolidation methods and processing steps to produce the product to be welded. These different products will have correspondingly different chemical analysis, different microstructures, different degrees of anisotropy, and different mechanical properties. Because of the relatively low tensile ductility (1 to $6 \%$ ) of essentially all theses products, small changes in these factors will affect the weldability of the beryllium.

Fusion welding is limited to methods where either a vacuum or complete shielding from the ambient atmosphere is used. Welding operations should be designed to minimize heat input, thermal stresses, grain growth, and the concentration of weld defects. The process that produces the smallest weld zone usually provides the best results. The two most common methods used for fusion welding of beryllium are gas-tungsten-arc (GTA) ${ }^{\mathrm{g}}$, also known as tungsten inert gas (TIG), and electron-beam $(\mathrm{EB})^{\mathrm{h}}$ processes. Beryllium can also be welded by gas-metal-arc welding $(\mathrm{GMAW})^{\mathrm{i}}$, also known as metal inert gas (MIG) and by pressurized-gas-metal-arc welding (PGMA) ${ }^{\mathrm{j}}$. Of these two, PGMA is preferred; however, both methods produce higher heat inputs than those obtained by GTA or EB. The benefits of pressure used with PGMA are the reduction of porosity and arc-column diameter. ${ }^{3}$ The GMAW process requires an aluminum-silicon filler wire and demands careful cleaning as well as good chemical homogeneity of the beryllium.

The EBW process produces welds with a high depth-to-width ratio (10:1 to 30:1) and a narrow heat-affected zone (HAZ). The sides of the weld are almost parallel. The narrow fusion zone and the relatively low heat input obtained with the EBW process lead to a reduction of thermal stress and distortion, thus reducing the tendency for cracking. Also, it permits the welding of parts that already have been machined without the need for any further size adjustment. In addition, the high depth-to-width ratio often allows for single-pass welding, which results in a further reduction

\footnotetext{
${ }^{\mathrm{g}}$ The Gas-Tungsten Arc welding process is a process that uses heat produced by an arc generated between a nonconsumable electrode (tungsten or tungsten alloy) and the workpiece. The electrode and weld region is shielded from the ambient atmosphere by a shielding gas that is supplied through the torch.

${ }^{\mathrm{h}}$ The Electron-Beam-Welding (EBW) process is a high-density-fusion process that is accomplished by bombarding the joint to be welded with an intense, strongly focused beam of electrons. The instantaneous conversion of the kinetic energy of these electrons into thermal energy as they impact and penetrate into the workpiece causes the weld-seam interface surfaces to melt, producing the desired weld-joint coalescence.

${ }^{\mathrm{i}}$ Gas-metal-arc welding (GMAW) is an arc-welding process in which the heat for welding is generated by an arc between the workpiece and a consumable electrode that is shielded by an externally supplied protective gas. The electrode is a bare solid wire, which serves as the filler metal (metal added to the weld pool) that is continuously fed to the weld area.

${ }^{\mathrm{j}}$ Pressurized-gas-Metal-Arc (PGMA) welding is an adaptation of the GMAW process using pressurized gas.
} 
of the size of the HAZ. Because of the vacuum environment, the need for shielding of the molten metal from the ambient atmosphere is not needed. Because of the relatively high vapor pressure ( $25 \mu \mathrm{m} \mathrm{Hg}$ at the melting point) of beryllium, both heat input and vacuum should be preferably limited, the latter to about a pressure of about $10^{-4}$ torr. The electron beam welding of beryllium is usually done at pressures between $10^{-6}$ and $10^{-3}$ torr; however, the process can be adapted for pressures to as high as $10^{-1}$ torr. The penetration and the depth-to-width ratio are both reduced as the pressure is increased. For most materials, foil to plate thicknesses are weldable in one pass. The EBW process allows for high welding speeds (125 to $200 \mathrm{~mm}$ per second) on sheet material and requires no filler metal, flux, or shielding gas.

In the EBW process, an aluminum shim can be placed between the two beryllium parts to be joined, the aluminum typically being high-purity1 100 sheet. The aluminum shim must be in good contact with one of the parts. With large assemblies, this may create a problem. An alternative method that was developed was to deposit the aluminum on the mating surface (which could be an edge) using physical vapor deposition (PVD). ${ }^{9}$ Surfaces that are not to be plated are carefully masked.

In an early EBW investigation, it was observed that in order to obtain a satisfactory joint using a shim, it was necessary to melt the beryllium on both sides of the shim. ${ }^{10}$ By focusing along the center of the joint, a fusion zone with nearly parallel sides was obtained. Focusing off the weld centerline resulted in poor wetting of the aluminum to the beryllium on one side of the weld and cracking in the beryllium on the other side. Throughout the fusion zone the structure consisted of primary beryllium dendrites in an Al-Be eutectic ${ }^{\mathrm{k}}$ matrix. The authors observed that the top of the joint consisted of a columnar structure, whereas at the bottom (root) of the joint the structure tended to be equiaxed ${ }^{1}$ as well as being finer than the structure at the top. This was attributed to a decrease in the width of the fusion zone in going from top to bottom resulting in a corresponding increase in the solidification rate. In addition, the beryllium content and hence the melting point were higher at the top of the joint than at the bottom of the joint. They noted that in order to produce a sound, crack-free, high-strength weld, the fusion zone had to contain over $30 \mathrm{wt} \%$ of aluminum. Alloys 1100, 2024, 5052, 5083, 6061, and 718 were evaluated for use as shims. All except 2024 produced joint strengths equal to or greater than the strength of the beryllium. Alloy 718 showed the best fluidity.

In the GTA welding process, the joint is produced by heating the abutting parts with an arc formed between a tungsten electrode, which is nonconsumable, and one of the parts. One or more electrodes may be simultaneously used. Protective inert-gas shielding is required. Filler metal, if needed, can be used. The base-metal thickness and joint design determine whether filler metal should be added to the joint. The parts being welded must be firmly secured relative to each other. Additional fixturing may be necessary when fit-up is marginal, parts are thin, shapes are complex,

\footnotetext{
${ }^{\mathrm{k}}$ The term eutectic refers to a microstructure that forms due to the solidification of a liquid phase into two or more solid phases. The solid phases precipitate out of the liquid sequentially, continuously repeating the sequence until all the liquid has solidified resulting in an intimate mixture of the solid phases.

${ }^{1}$ The term equiaxed refers to the grains of a microstructure having no morphological orientation; i.e., all axes drawn through the center of and within a grain are essentially equal
} 
filler metal is not used, or automatic or machine welding is used. The filler metal as well as the mating and adjacent surfaces must be clean.

In welding manually, the filler rod is added into the pool of molten metal ahead of the arc. Improper electrode and rod angles may degrade the weld. The recommended angles are $15^{\circ}$ backwards and $75^{\circ}$ forward from the vertical to the work surface, in the travel direction, for the electrode and filler rod, respectively. All standard joints can be welded by this method. Generally, edges need not be beveled for thicknesses of $3.2 \mathrm{~mm}$ or less. Thicker base parts are usually beveled and the aluminum filler metal is always added. The GTA welding process can be used for continuous welds, intermittent welds, and spot welds. It can be done manually or automatically.

Because of the excellent control of heat input, the GTA process is especially good for joining thin parts. Another good feature is that the heat source and addition of filler can be separately controlled. Some disadvantages or limitations do exist. The process is slower than a consumable electrode process. Some transfer of tungsten from the electrode to the weld metal could occur, resulting in brittle tungsten inclusions. Costs are generally higher than those for other welding processes.

In the GMAW process, heat is generated by an arc developed between an electrode and the weld pool. The electrode is a bare solid wire that is continuously fed to the weld area, thus becoming the filler metal as it is consumed. A cover gas that is fed through the welding gun provides protective shielding from the ambient atmosphere. Inert gases are used. The process may be operated in a semiautomatic or automatic mode. Because of the continuous feed of filler metal, long welds can be made without interruptions. The process enables the attainment of relatively high deposition rates and welding speeds. The arc must be protected against air drafts that could disperse the shielding gas.

To further minimize cracking, the feasibility of welding beryllium by Pulsed Gas Tungsten ArcBraze-Spot Welding(GTA-B-SW) ${ }^{\mathrm{m}}$ with preplaced aluminum shims was evaluated. ${ }^{5}$ The concept was to have rapid solidification that would result in a continuous and intimate mixed region of beryllium and aluminum. The concept was based on thermodynamic calculations that a liquid miscibility gap ${ }^{\mathrm{n}}$ exists in the liquid + solid region in the Al-Be system at high Be concentrations. The welding experiments were performed on 2-mm-thick, 20-mm-diameter rings, machined out of beryllium rods. A schematic sketch of the joint design is reproduced in Fig. X-1-7. The shims consisted of 0.3-mm-thick 1100 aluminum strips. Both the aluminum and beryllium were cleaned by acid etching prior to welding. The etchants were $10 \% \mathrm{H}_{2} \mathrm{SO}_{4}-48$ grams $(4 \%) \mathrm{H}_{2} \mathrm{CrO}_{4}-1 \% \mathrm{HF}$ $85 \% \mathrm{H}_{2} \mathrm{O}$ for $\mathrm{Al}$ and $2 \% \mathrm{HF}-48 \% \mathrm{HNO}_{3}-50 \% \mathrm{H}_{2} \mathrm{O}$ for Be. Welds were evaluated by radiographic inspection and optical and scanning electron microscopy of transverse sectioned samples.

\footnotetext{
${ }^{\mathrm{m}}$ Term created for an experimental process. The pulsed arc was obtained using the GTAW process. The inclusion of "braze" is related to the use of a shim insert similar to its use in a brazing process.

${ }^{\mathrm{n}}$ A liquid miscibility gap refers to the region on the phase diagram where over a temperature range the liquid has separated into two liquids of different compositions in equilibrium with each other.
} 
The authors observed that the microstructure had a component that was typical of a pure eutectic, i.e., a very fine dispersion of Be (primary phase) in continuous Al (secondary phase). The beryllium nucleated, forming dendrites with the aluminum back-filling along the interdendritic zones. The aluminum from the fusion zone (FZ) extended along grain boundaries into the base metal heat-affected zone (HAZ) forming aluminum stringers. These stringers absorbed the thermal strain, thus, inhibiting crack branching and crack propagation in the FZ. The surface of the FZ, however, was found to be sensitive to hot cracking. 5

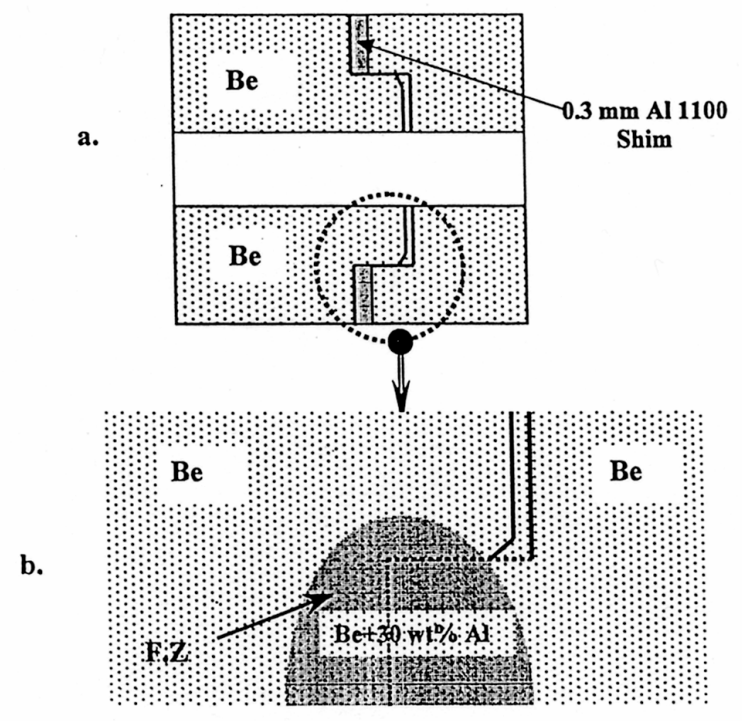

Fig. X-1-7 Schematic sketch of joint design. ${ }^{5}$ (a) before welding, (b) enlargement of fusion zone following welding.

\section{$\underline{X-1-4-P o r o s i t y ~ i n ~ W e l d s ~}$}

In welding the closure of beryllium pressure vessels, Dow Chemical Company reported having porosity in the MIG welds. Of special concern were those voids of macroscopic size, i.e., discernable with the naked eye. The porosity was attributed to the hydrogen dissolved in the molten aluminum filler metal. The drop in solubility on solidification and on cooling of the solid results in the formation of pores as the excess hydrogen is expelled from solution. The solubility of hydrogen in aluminum as a function of temperature is shown in Fig. X-1-8. The hydrogen could originate from a number of sources: filler metal, moisture on the filler wire, beryllium, shielding gases, and greases and lubricants used in the manufacture of the wire or parts to be welded. ${ }^{11}$ Calculations show that $10 \mathrm{ppm}$ by weight of hydrogen will produce a volume of $1 \%$ of the solid during solidification. An evaluation of wires revealed six and $13 \mathrm{ppm}$ of hydrogen in an Alcoa and in Allstate Al-12\%Si wire , respectively. Other gases were also present; of these about $80 \%$ was hydrogen, and $20 \%$ was a mixture of methane and other gases. Cleaning the wire will reduce the amount of porosity. However, if the cleaning agents are not completely removed, the porosity may be increased. Trichloroethylene was suggested as a degreasing agent.

The most satisfactory welding process to minimize the effects of weld porosity is PIGMA It is suggested that the pressure increase tends to keep the dissolved gases in solution for the melt to 
partially solidify. The smaller gas bubbles that form are then unable to readily move through the discontinuous melt and coalesce to form large bubbles and lead to large voids. Significant reduction in macroporosity was realized by PIGMA welding when the chamber pressure was raised to between 69 and $103 \mathrm{kPa}$ (gage). ${ }^{11}$

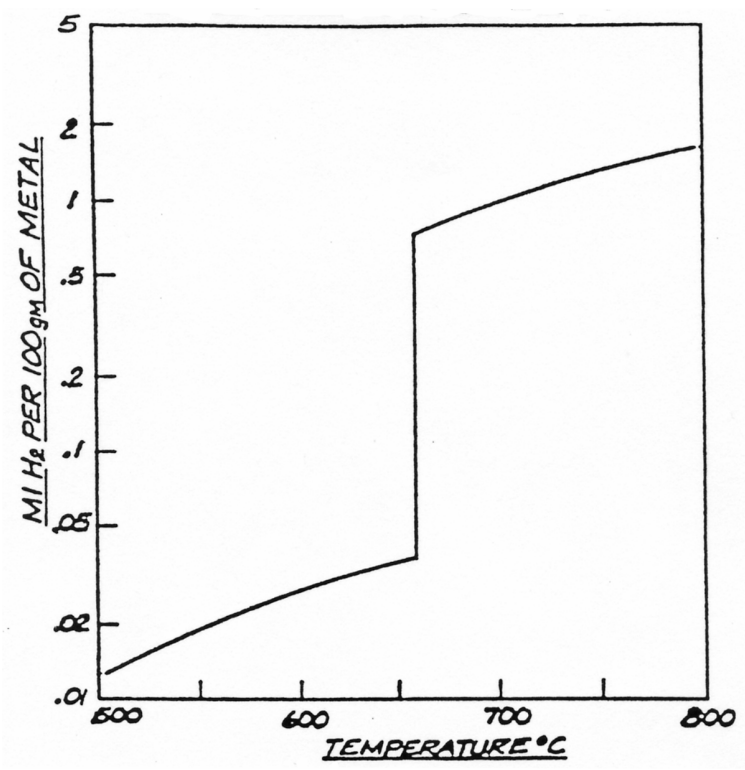

Fig. X-1-8 Solubility of hydrogen in aluminum at atmospheric pressure. ${ }^{11}$

\section{$\underline{\mathrm{X}-1-5-\text { Surface Preparation }}$}

Surfaces must be carefully cleaned prior to welding. This can be done by degreasing using a combination of acetone and alcohol wipes. If the surfaces appear heavily oxidized or not properly degreased, then they should be chemically etched with a $5 \%$ solution of hydrofluoric acid and deionized water. A slight tendency for pitting may occur. An alternative cleaning solution that has a lesser tendency for pitting is a solution of $70 \%$ phosphoric acid, $25 \%$ sulfuric acid, and $25 \%$ nitric acid. Care must be taken that the filler wire is not contaminated with lubricant.

Cleaning reported in an early investigation evaluating EB welding of beryllium using preplaced shims of different aluminum alloys consisted of the following. ${ }^{10}$ The beryllium was cleaned by etching with a solution composed of $2 \% \mathrm{HF}, 3 \% \mathrm{HOOCCH}_{2} \mathrm{COOH}$ (malonic acid), $5 \% \mathrm{HNO}_{3}$, and $90 \% \mathrm{H}_{2} 0$. The beryllium was immersed in the solution until the reaction appeared to stop. Approximately $25 \mu \mathrm{m}$ of material was removed from each surface. The shims were cleaned with Tuckers etch $\left(10 \% \mathrm{HF}, 15 \% \mathrm{HCl}, 25 \% \mathrm{HNO}_{3}\right.$, and $\left.50 \% \mathrm{H}_{2} \mathrm{O}\right)$. The aluminum alloys were etched until about $12 \mu \mathrm{m}$ of material was removed.

Surface damage due to heavy tool forces in machining can provide nucleation sites for cracking during welding. Each of the final three cuts should be less than $76 \mu \mathrm{m}$ deep. 


\section{$\underline{X-1-6-F i l l e r ~ M e t a l s ~ a n d ~ F e e d ~ R a t e s ~}$}

Aluminum-alloy filler wires have been used successfully for welding beryllium. The most successful of these is alloy 718 containing $12 \%$ silicon, which, being close to the eutectic composition, results in a relatively high-fluidity, low melting-point aluminum-rich fusion joint. The melting point is sufficiently low to promote liquid formation and backfilling of cracks. The drawbacks of adding an aluminum-alloy filler include a reduction of service temperature and a lowering of the tensile strength of the weld. ${ }^{3}$. It is recommended that the filler wires contain at least $30 \mathrm{wt} . \%$ (approx. 10 at.\%) Al to suppress cracking at room temperature.

Wire-feed rate ranges from about 190 to $380 \mathrm{~mm} / \mathrm{sec}$, depending on groove size. ${ }^{7}$ The starting feed rate is about $25 \%$ of the continuous rate. The weld travel speed is of the order of 17 to 21 $\mathrm{mm} / \mathrm{sec}$. Typical power settings are 30 to $32 \mathrm{~V}$ and 140 to $150 \mathrm{Amps}$ at direct current electrode positive. Welding machines with voltage characteristics of a medium slope perform somewhat better than one having a flat slope ${ }^{o}$ (constant potential). The former machines, having a slightly smaller arc length, avoid producing an arc blast at the start. ${ }^{7}$

Satisfactory welds are made in two passes with the GMAW process using Alcoa 718 filler wire of $0.762 \mathrm{~mm}$ diameter, fed at a rate of about $380 \mathrm{~mm} / \mathrm{sec}$ with a travel feed of about $38 \mathrm{~mm} / \mathrm{sec}$. Other parameters include a reverse polarity arc voltage of 22 volts, and gas flows of helium at $2.83 \mathrm{~m}^{3} /$ hour and of argon at $0.51 \mathrm{~m}^{3} /$ hour. Different numbers of passes are made with appropriate parameter changes. The PIGMA process is similar to the GMAW process except that it is performed in an inert-gas chamber that is at a pressure above atmospheric. Except for a slightly higher voltage with the PIGMA process, both use similar parameters.

Welding parameter ranges reported by Dow Chemical Company used in the GMAW process for welding equatorial closures of beryllium-pressure vessels and using aluminum alloy 718 filler metal $(0.762 \mathrm{~mm}$ dia.) were as follows: 250 to $380 \mathrm{~mm} / \mathrm{sec}$ wire-feed speed;18 to $51 \mathrm{~mm} / \mathrm{sec}$ travel speed; 135 to $200 \mathrm{Amps}^{\mathrm{DCRP}}{ }^{\mathrm{p}}$ weld current; 22 to $30 \mathrm{~V}$ arc voltage; 120 to 210 percent joint fill; 1.42 to $2.83 \mathrm{~m}^{3} /$ hour of helium, 0.38 to $0.51 \mathrm{~m}^{3} /$ hour of argon; 0 to $69 \mathrm{kPa}$ (gage) pressure; and 6.35 to $9.53 \mathrm{~mm}$ for contact tip-to-work distance. It is suggested that the filler metal be deposited directly into a "V" or "U" grooved joint.

Improved strength was obtained using a two-step process. This consisted of depositing a layer of alloy 718 onto the mating surfaces. The surfaces were then machined so as to form an aluminum alloy "V" at the closure area when the components were assembled to be welded. Such a joint has been referred as a "buttered joint."

\footnotetext{
${ }^{\circ}$ Slope refers to the voltage-versus amperage curve. It is a characteristic of the power supply. A flat slope refers to an essentially constant voltage supply attainable with a power supply having a relatively low resistance. Power supplies are available to provide a range of slopes such that the amperage can be controlled with voltage changes. Different welding processes perform best at different slopes.

${ }^{\mathrm{p}}$ In direct current reversed polarity (DCRP), the electrons flow from workpiece to electrode instead of from electrode to workpiece.
} 
A series of high-speed motion pictures were used to evaluate the effect of wire-feed speed on the weld characteristics. The travel speed was adjusted to produce a constant 150 percent joint fill. The tests were performed using MIG welding, with alloy 718 filler metal, and at an arc voltage of $28 \mathrm{~V}$. The films revealed that at low speeds (167 to $250 \mathrm{~mm} / \mathrm{sec}$ ), the arc was very long, the puddle possessed little fluidity and the beryllium bonded poorly to the aluminum weld metal. Increasing the feed speed between 300 and $420 \mathrm{~mm} / \mathrm{sec}$, results in a considerable shortening of the arc length and good bonding was obtained. On further increasing the feed speed to 460 $\mathrm{mm} / \mathrm{sec}$, the arc becomes increasingly shorter with bonding occurring only at the root of the weld. Signs of arc instability appeared with rough surfaces of the weld deposits. At $22 \mathrm{~V}$, the optimum feed speed was $340 \mathrm{~mm} / \mathrm{sec}$.

Electron-beam welds made without a filler metal usually tend to crack. Without a filler metal, the process is limited to sheet material about 0.58 to $0.76 \mathrm{~mm}$ thick. Typical welding parameters using an aluminum alloy filler for an EBW joint, requiring a $2.54-\mathrm{mm}$ penetration, are: $70 \mathrm{kV}, 7.5$ $\mathrm{mA}$; a travel speed of $6 \mathrm{~mm} / \mathrm{sec}$; and, with the beam focused at a point $6.35 \mathrm{~mm}$ above the joint. ${ }^{12}$ To avoid any movement of the filler-metal shim, the shim can be spot welded to the workpiece. Alternatively, the filler metal can be vapor deposited on to the part.

\section{$\underline{\mathrm{X}-1-7-\text { Shielding }}$}

Helium and argon gases are used for shielding the molten and solidifying weld metal from the atmosphere. Weld-metal porosity is lower with helium than it is with argon. However, some argon is required to obtain a smooth bead contour, and in small amounts the argon does not degrade the quality of the weld; thus, both gases are used together. ${ }^{11}$ A combination of five parts helium to one part argon by volume is recommended as a gas shield. Typical flow rates are 1.4 to $2.8 \mathrm{~m}^{3} /$ hour of helium and 0.28 to $0.57 \mathrm{~m}^{3} /$ hour of argon, the rate depending mainly on the type of weld chamber. The higher flow rates should more likely lead to contaminant-free welds.

\section{$\underline{\mathrm{X}-1-8 \text { - Joint Design }}$}

Various joint designs that have been used in 3.2-mm-thick beryllium sheet include the following: lap joints, tee joints, corner-lap joints, corner-butt joints, and butt joints between sheets of unequal thickness. ${ }^{3}$ Some examples of joints are shown in Figs. X-1-9. Additional illustrations of joints are presented in the section on Solid State Bonding.

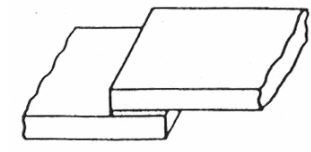

Lap joint

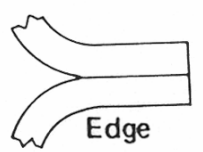

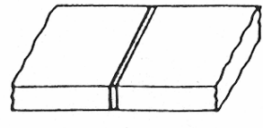

Butt joint

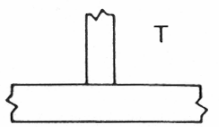

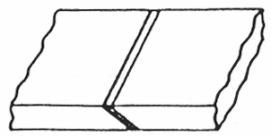

Scarf joint

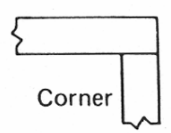

Fig. X-1-9 Schematic examples of some common joints. 
A sharp notch is present at the interface of lap, corner-lap, and tee joints that will limit the use of these joints to applications with low service stresses. Crack-free, full penetration butt welds have been made in beryllium-ingot sheet up to $3.8 \mathrm{~mm}$ thick. Joint designs and fixturing should be selected to minimize the restraint of the part. An example of a commonly used weld-joint design for plate and tube, based on butt joints prepared with a narrow "J" or "U" or with a narrow "V" with a root radius, is shown in Fig. X-1-10. Each groove follows the shape of the welding arc to minimize thermal shock to the base metal. The weld-root depth should not be less than $1.52 \mathrm{~mm}$. Weld penetrations of up to $6.35 \mathrm{~mm}$ may be obtained without preheat - with larger penetrations, preheating is necessary ${ }^{7}$.

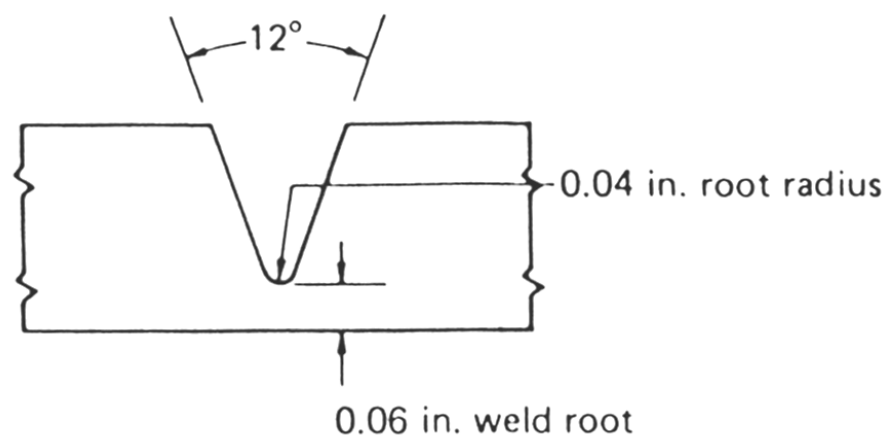

Fig. X-1-10 Double-U-groove joint commonly used in GMAW of beryllium plate and tube. $^{7}$

With electron-beam welding, the design is limited to either a tight butt or lap joint. As a rule, fitup $^{\mathrm{q}}$ is usually $0.12 \mathrm{~mm}$ or less and, usually, the root opening (joint gap) should not exceed 0.25 $\mathrm{mm}$ for weld depths less than $13 \mathrm{~mm}$.

\section{$\underline{\mathrm{X}-1-9-\text { Weld repair }}$}

Defects, such as porosity, can be repaired by machining out the defect and then preheating to $100^{\circ} \mathrm{C}$ and rewelding. If the pass is stopped, as may occur in a multiple-pass weld, then the part should be reheated before arc restart to reduce the possibility of cracking. ${ }^{7}$

\section{X-2-Brazing}

\section{$\underline{\mathrm{X}-2-1-\text { Introduction }}$}

Brazing is an economically attractive process for producing high-strength metallurgical bonds while retaining the desirable properties of the base metal. In brazing, a joint is obtained by heating the parts to be joined and the filler metal to a suitable temperature that will not melt the workpiece and will avoid or limit the introduction of any undesirable microstructures. It is considered to be an economical process that produces a high-strength bond while preserving the base-metal

\footnotetext{
${ }^{\mathrm{q}}$ The term fit-up refers to spacing between mating surfaces.
} 
properties. A filler metal is used that has a liquidus ${ }^{\mathrm{r}}$ above $450^{\circ} \mathrm{C}$ and a melting point below the solidus $^{\mathrm{s}}$ of the parts to be joined. The faying surfaces are first coated with a flux that melts while the parts are being heated. The flux dissolves any metal oxides present as well as prevents new oxidation. The filler is then added at some point on the surface of the joint and then drawn into it. For this to occur, the filler metal must wet the base-metal surfaces and be drawn into and held in the joint by capillary attraction, which is due to the an appropriate surface tension difference between base metal and filler. Thus, good wetability and fluidity are important characteristics of the filler. The filler metal must also be capable of displacing the flux due to their relative surface tensions and densities such that, after cooling, the joint is filled with solid filler metal while the solid flux will be found at the joint periphery.

Capillary flow is the dominant physical action that assures having a good braze providing that both faying surfaces are wet by the molten filler metal. Furthermore, the joint must be properly spaced to enable the capillary action to be efficient. Metallurgical reactions between the base metal and the filler metal could change the flow characteristics.

The advantages in the use of brazing over fusion welding include the following:

- lower heating temperatures,

- minimization, or elimination of warping,

- increased joining speed,

- higher production rates when simultaneous brazing a number of parts,

- reduction of the effects of expansion, contraction, and distortion,

- reduction of residual stresses, and

- more cost effective.

Brazing processes are generally designated according to the heating sources. Of industrial importance are: furnace brazing, induction brazing ${ }^{\mathrm{u}}$, torch brazing ${ }^{\mathrm{v}}$, resistance brazing ${ }^{\mathrm{w}}$, dip brazing $^{\mathrm{x}}$, diffusion brazing ${ }^{\mathrm{y}}$, and infrared brazing ${ }^{\mathrm{z}}$. Other methods include blanket brazing and exothermic brazing. All these methods use a filler metal that has a melting point above $450{ }^{\circ} \mathrm{C}$,

\footnotetext{
${ }^{\mathrm{r}}$ The liquidus is the boundary between the liquid region and liquid-plus-solid region on a phase diagram; i.e, the material is completely molten above the liquidus temperature. The temperature varies with composition.

${ }^{\mathrm{s}}$ The solidus is the boundary between the solid region and liquid-plus-solid region on a phase diagram; i.e, the material is completely solid below the solidus temperature. On heating, melting is initiated on reaching this temperature. The temperature varies with composition.

${ }^{\mathrm{t}}$ Furnace brazing is performed using a heated furnace.

${ }^{\mathrm{u}}$ Induction brazing uses the heat from the resistance of the workpieces subjected to a voltage induced through one or more coils.

${ }^{\mathrm{v}}$ Torch brazing is a brazing process that uses heat from a fuel-gas flame.

${ }^{\mathrm{w}}$ Resistance brazing is a brazing process that uses heat from the resistance of the workpieces to current flow in an electrical circuit.

${ }^{\mathrm{x}}$ Dip brazing is a brazing process that uses heat from a molten chemical or metal bath. The molten chemical bath may also serve as the flux, while the molten metal bath may serve as the filler metal.

${ }^{\mathrm{y}}$ Diffusion brazing is a brazing process that forms liquid braze metal by diffusion between dissimilar base metals or between base metal and filler metal preplaced at the faying surfaces. The process is used with the application of pressure.

${ }_{\mathrm{z}}^{\mathrm{p}}$ Infrared brazing is a brazing process that uses heat radiated from an infrared source.
} 
but below that of the base metal. The liquid filler metal spreads through the joint by capillary action. A brazing method that does not depend on capillary action is referred to as "braze welding." Here, the filler metal is deposited directly to where it will be used. The distinction between brazing and soldering is based on the melting temperature of the filler. In soldering, filler metals melt below $450^{\circ} \mathrm{C}$

\section{$\underline{\mathrm{X}-2-2-\text { Selection of Brazing Process }}$}

Beryllium reacts rapidly with oxygen to form very stable oxides. It has a high solubility for oxygen, nitrogen, and hydrogen at elevated temperatures. Small amounts of any of these elements will result in an increase in hardness, notch sensitivity, and embrittlement. In addition, the oxidized and nitrided surfaces will impair the wetability and flowability of the brazing filler metals. To avoid these problems when brazing beryllium, surfaces of the parts to be brazed must be prevented from being exposed to air during heating. Therefore, beryllium must be brazed in vacuum or in a high-purity inert gas. Induction and furnace brazing in inert gas or vacuum can be used successfully. If not in vacuum, then an argon or helium atmosphere is recommended. Torch brazing should generally not be used for beryllium. It is difficult and requires special precautions and techniques. Induction brazing is favored for small, symmetrical parts because its speed minimizes reaction between filler metal and base metal. Furnace brazing is favored for large parts since the uniformity in temperature required throughout the heating and cooling cycle can be readily controlled. ${ }^{6}$ In general, a vacuum environment is preferred. To minimize the formation of intermetallics between beryllium and braze constituents, short heating, holding, and cooling times are recommended.

Furnace brazing is especially applicable to high-rate production. Here, the filler metal must be preplaced at or near the joint. The filler metal can be in one of many forms: wire, foil, tape, paste, slugs, powder, filings, etc. Fluxes are used to protect the parts and brazing filler metal except where an atmosphere of reducing or inert gases are used for the same function. Vacuum-furnace brazing, in preventing oxidation, eliminates the need for a flux. This method is widely used where reactive metals are joined or where entrapped fluxes cannot be tolerated. Filler metals that contain constituents with high vapor pressures should not be used for brazing in vacuum or under significant continuous pumping used to maintain the vacuum.

In induction brazing, the filler metal is generally preplaced at the joint. To assure that all the faying surfaces reach the brazing temper at the same time, the joint and coil setups must be carefully designed and integrated. Special attention must be given to the coil design for parts having widely varying thicknesses. Sheet thickness normally does not exceed $3 \mathrm{~mm}$, while bar thickness can be as high as $25 \mathrm{~mm}$. Brazing temperatures are reached in less than 10 seconds, allowing for high production speeds.

\section{$\underline{\mathrm{X}-2-3-\text { Surface Preparation }}$}

Beryllium surfaces must be thoroughly cleaned before brazing. Components should be degreased, and then pickled in an aqueous solution of $10 \% \mathrm{HF}$ or $40 \% \mathrm{HNO}_{3}-5 \% \mathrm{HF}$, followed by an ultrasonic rinse with deionized water and dried. ${ }^{13}$ Because the presence of an oxidized or nitrided 
surface impairs the wetting and flow properties of brazing filler metals, high-temperature brazing should be done in a protective atmosphere, such as in argon, helium, or vacuum. Titaniumhydride $(\mathrm{TiH})$ flux is suggested as a very effective flux, especially for silver-containing braze alloys. ${ }^{12}$ The TiH can be painted on to the beryllium surface.(Additional reference to fluxes is presented in section 4-4.).

Precoating the joint faying surfaces by either vacuum metallizing or electroplating with silver, titanium, copper, aluminum, or AWS BAlSi-4 filler metal prior to brazing is effective for improving wetability. Reoxidation of the precleaned surface can be prevented by the application of a thin film of amylacetate, which readily burns off at brazing temperatures. ${ }^{13}$ A vapordeposited titanium coating may be very effective in promoting wetability. The titanium drastically changes the beryllium surface, promoting extensive spreading and wetting when pure aluminum filler metal is used. Placement of titanium hydride may be used instead of vapor depositing. The hydride is mixed with commercial brazing cement (polyethyl methacrylate and 1, 1, 1trichloroethane). The cement decomposes during brazing in vacuum at about $540^{\circ} \mathrm{C}$. The hydride decomposes at $660^{\circ} \mathrm{C}$ leaving a layer of titanium on the surface. ${ }^{13}$

\section{$\underline{\mathrm{X}-2-4-\text { Filler Metals }}$}

Beryllium reacts with the constituents of most filler metals used for brazing, which may result in the formation of undesirable intermetallic compounds. Grain boundary penetration into the beryllium may also be a problem. Brazing should be done under conditions that minimize the formation of intermetallic compounds: rapid heating and cooling cycles, low brazing temperatures, minimum time at brazing temperatures, and minimum amounts of filler metal. Beryllium reacts with oxygen and atmospheric nitrogen at conventional brazing temperatures. Oxidized or nitrided surfaces will impair the wetability and flowability of filler metals. Beryllium assemblies braze best in argon or helium gas. The choice of a specific filler metal or the need for a specific design can limit the choice of the optimum brazing procedures. Beryllium can be wetted directly by aluminum brazing alloys. Many of the filler metals, however, do not wet or flow well on beryllium. As a result, the filler metal must frequently be preplaced between the joint members in amounts sufficient to produce the brazed joint. Longer brazing times than desired may be required to ensure proper wetting and flow of the filler metal, which may adversely affect the joint properties. Surfaces may be plated with silver to improve wetability and flowability of the filler metals. In general, preplacement of the filler metal is recommended. Even so, outside corners and edges of the joint may show a lack of adequate filler-metal flow, simulating a notch. Such defects may have to be machined to a smooth surface in order to avoid the severe notch sensitivity of beryllium.

Filler metals with narrow melting ranges and at eutectic compositions, which behave like a pure metal during melting, are best for applications having small joint clearances (25 to $80 \mu)$. With filler metals having a wide melting range, separation of solid and liquid phases may occur when using too slow a heating rate during brazing. ${ }^{13}$ The compositions of the solid and liquid continually change as the temperature rises with the liquation (initiation of melting) temperature of the unmelted (solid) portion rising, while the liquation temperature of the corresponding liquid portion is dropping. Under these conditions (approaching equilibrium), there is sufficient time for 
some of the lower melting liquid portion to escape leaving behind an unmelted "skull" of the higher melting solid as its liquation temperature may be at the brazing temperature. This behavior is more likely to occur with a preplacement filler.

Metallurgical compatibility between the filler metal and beryllium as well as with any mating materials is mandatory. The likelihood of forming brittle intermetallic compounds, e. g., beryllides, must be avoided. Only four metals do not form stable beryllides below $760^{\circ} \mathrm{C}$ :aluminum, silicon, silver, and germanium. ${ }^{14}$ Intergranular penetration into hot-pressed beryllium block was found not to be harmful. A two-phase structure formed consisting of primary beryllium grains surrounded by a silver matrix. Very limited mutual solubility, especially of Be in $\mathrm{Ag}$, exists between the two elements. This microstructure is reported as exhibiting outstanding strength and toughness properties. ${ }^{14}$ The penetration of silver into beryllium as a function of time above $760^{\circ} \mathrm{C}$ is shown in Fig. X-2-1.

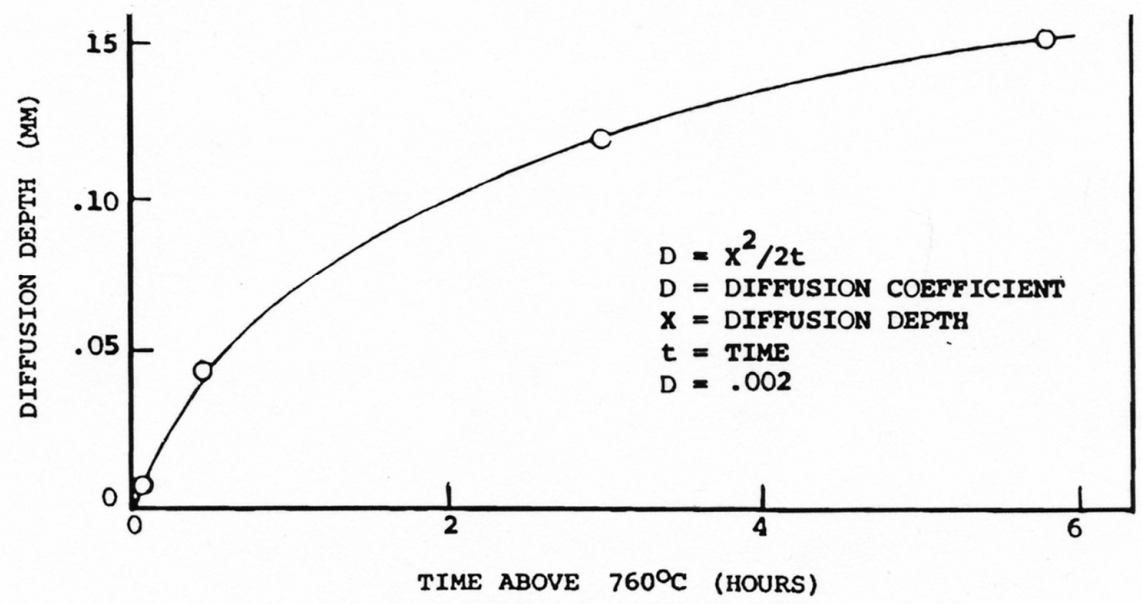

Fig. X-2-1 Diffusion depth of silver from BAg-18 into beryllium as a function of brazing time just above $760^{\circ} \mathrm{C} .{ }^{14}$

Filler metals used for brazing beryllium include silver, silver-based alloys, aluminum, and aluminum-silicon alloys. Silver and silver-based filler metals, such as BAg-18 (Ag-30\%Cu$10 \% \mathrm{Sn}), \mathrm{BAg}-19(\mathrm{Ag}-7 \% \mathrm{Cu}-0.2 \% \mathrm{Li})$, and BAg-8a (Ag-28\%Cu-0.2 to $0.5 \% \mathrm{Li})$ are used for hightemperature applications. Lithium is added to the filler metal improve wetability. It has been suggested that silver alloyed with less than $8 \% \mathrm{Cu}$ exhibits an improvement in wetability over that of unalloyed silver. ${ }^{12}$ The aluminum-silicon filler metals, such as BAlSi-2 (7\% Si) and BAlSi-4 $(12 \% \mathrm{Si})$ can provide high strength brazed joints for service at temperatures up to $150^{\circ} \mathrm{C}$. These are suitable for high-strength wrought beryllium as the brazing temperatures are below that of the recrystallization temperature of beryllium. However, these fillers exhibit poor flow behavior in capillary joints, and must be preplaced in the joint. Small amounts of lithium may be added to pure silver to improve its wetability. Another filler metal suitable for beryllium is $64 \mathrm{Ag}-34 \mathrm{Cu}-$ 2Ti. ${ }^{13}$ Silver-copper fillers that melt at relatively low temperatures may exhibit less grainboundary penetration, although both elements can form brittle intermetallics at temperatures 
below the melting point of these fillers. These metallurgical problems (excessive alloying, grainboundary penetration, and intermetallics) can be avoided or minimized by using $\mathrm{Cu}-\mathrm{Ag}$ fillers that have small amounts of additives of either tin or lithium. ${ }^{13}$

Silver brazing has many advantages over aluminum brazing. Many of the original berylliumbrazing studies were done with silver. ${ }^{14}$ Silver brazing provides the ability to make transitions between beryllium and stainless steels and other alloys. Its major disadvantage is to cause a degradation of wrought-beryllium sheet products by recrystallization when the brazing temperature exceeds $730^{\circ} \mathrm{C}$. Two filler metals currently being used at LLNL for vacuum brazing are Cusil (72\% Ag-28\% Cu eutectic) and InCusil-ABA (59.0\% Ag-27.25\% Cu-12.5\% In-1.25\% Ti); the ABA stands for "active braze alloy." Cusil and Incusil are used to braze beryllium mainly to Monel and Cusil is also used for brazing to stainless steel. Additional braze compositions that have been used to vacuum braze beryllium joints are $\mathrm{Ag}-5 \% \mathrm{~Pb}, \mathrm{Ag}-15 \% \mathrm{~Pb}-20 \% \mathrm{Cu}, \mathrm{Cu}-18 \%$ $\mathrm{Pb}$, and $\mathrm{Ti}-6 \% \mathrm{Be}$.

Brazing-temperature ranges for several brazing-alloy compositions that are listed in the AWS Brazing Handbook ${ }^{13}$ are given in the following;

- Zinc:

- Aluminum-silicon

- Silver-copper

- Silver $427-454^{\circ} \mathrm{C}$

$566-677^{\circ} \mathrm{C}$

$649-904^{\circ} \mathrm{C}$

$882-954^{\circ} \mathrm{C}$

Fluxes are essential in producing brazed joints when not using an inert atmosphere or vacuum. An important function is to dissolve and remove oxides present or formed during brazing. It must, however, be readily displaceable by the molten filler metal and, thus, it must have a sufficiently low viscosity. A flux consisting of $60 \% \mathrm{LiF}-40 \% \mathrm{LiCl}$ and one consisting of a tin -chloride compound have produced good results when used for furnace or induction brazing. ${ }^{13}$ However, these two fluxes should not be used when brazing in vacuum. Fluxes may also be used to prevent oxidation or eliminate oxides during low-temperature brazing in air.

Following brazing, the brazed joint must be cleaned to remove any flux residue and any oxide scales that may have formed. Removal of flux residue is especially important, since many fluxes are chemically corrosive. Residual flux is removed with a hot water wash. If necessary, a wire brush may also be used.

\section{$\underline{\mathrm{X}-2-5-\text { Joint Design }}$}

Joint design, filler-metal selection, and choice of brazing cycle are complicated due to the low ductility of beryllium, as well as its reactivity with many of the filler metals used for brazing. The low ductility of beryllium is aggravated by the presence of structural discontinuities such as surface scratches, notches, and asymmetrical stress patterns produced by single-lapped joints. Joint configurations such as butt, scarf, step, and double-lap joints should be considered when 
designing beryllium structures. ${ }^{13}$ Preferably, joints that contain no notches should be used to achieve maximum reliability. ${ }^{6}$ Asymmetrical stress patterns such as produced by single-lap joints should be avoided.

The joint should be designed for proper stress distribution as well as accessibility for capillary flow of the filler metal when the parts are aligned for brazing. The design should provide for loads to be accommodated mainly by shear stresses across the deposited filler metal. The spacing between the mating surfaces must be sufficiently small to allow the filler metal to cover the entire surface by capillary action. A minimum amount of filler metal should be used, since a thin film of filler metal also provides for triaxiality ${ }^{\text {aa }}$ strengthening. Sufficient clearance, however, must be available to allow the escape of molten flux and gases during heating. Differences in the coefficient of expansion of the components must be taken into account.

Some examples of joints are shown in Figs. X-2-2, X-2-3, and X-2-4. Additional illustrations of joints are presented in the section on Solid State Bonding.

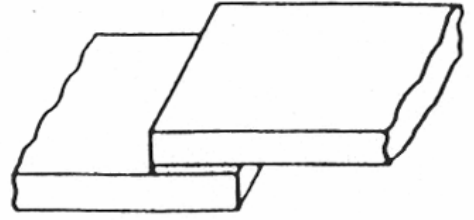

Lap joint

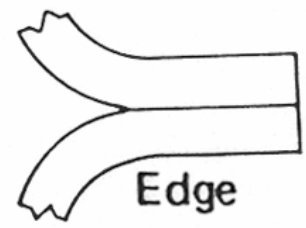

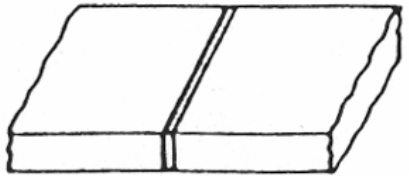

Butt joint

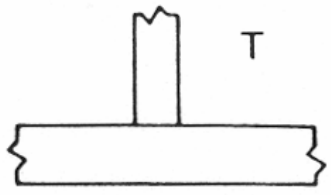

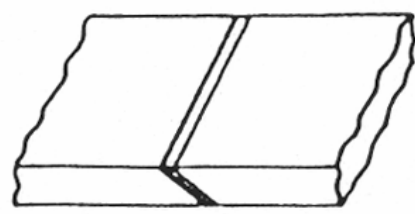

Scarf joint

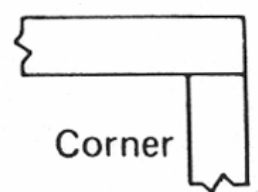

Fig. X-2-2 Schematic examples of some common joints.

\footnotetext{
aa Triaxiality results from the constraints imposed on the thin filler-metal interlayer by the mating surfaces.

Transverse stresses are imposed on the layer that keep it from contracting, which must occur in order for the layer to deform (elongate) in the tensile direction. Thus, the tensile deformation of the layer follows along with the elastic tensile deformation of the beryllium mating parts.
} 

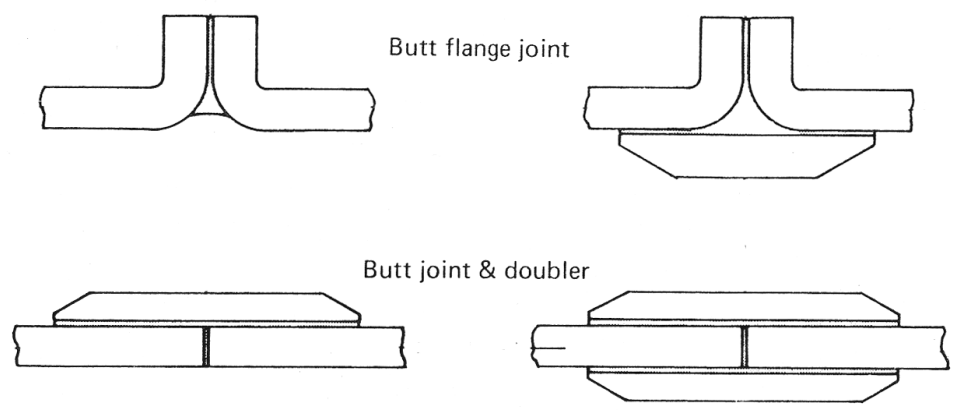

Fig. X-2-3 Butt-joint designs for sheet-metal brazements.

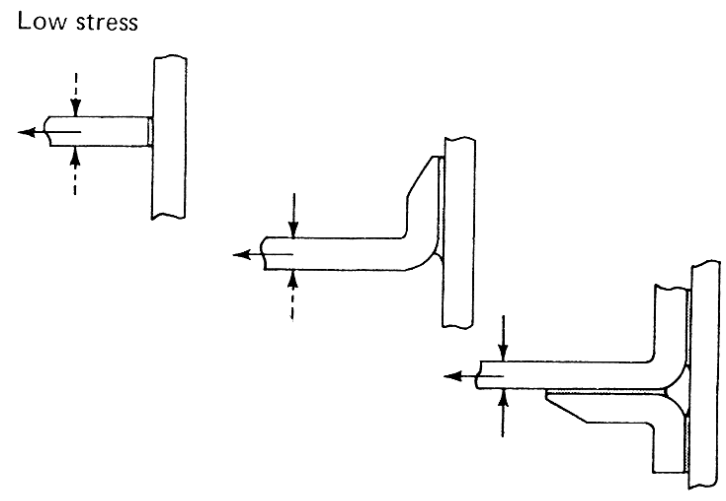

Fig. X-2-4 Tee-joint designs for sheet-metal brazements.

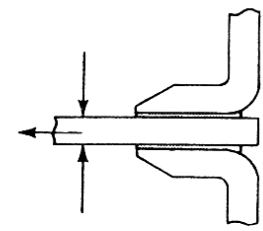

High stress

\section{$\underline{\text { X-2-6-Test Results of Brazed Joints }}$}

Screening tests of lap-shear specimens were performed to evaluate the potential use of four brazing alloys with beryllium for use at temperatures up to $650^{\circ} \mathrm{C} .{ }^{15}$ Information on the alloys is listed in Table X-2-1. The shear-strength results are shown in Fig. X-2-5. Cusil ABA performed poorly, even at room temperature, due to poor wetability during brazing. Furthermore, many of the

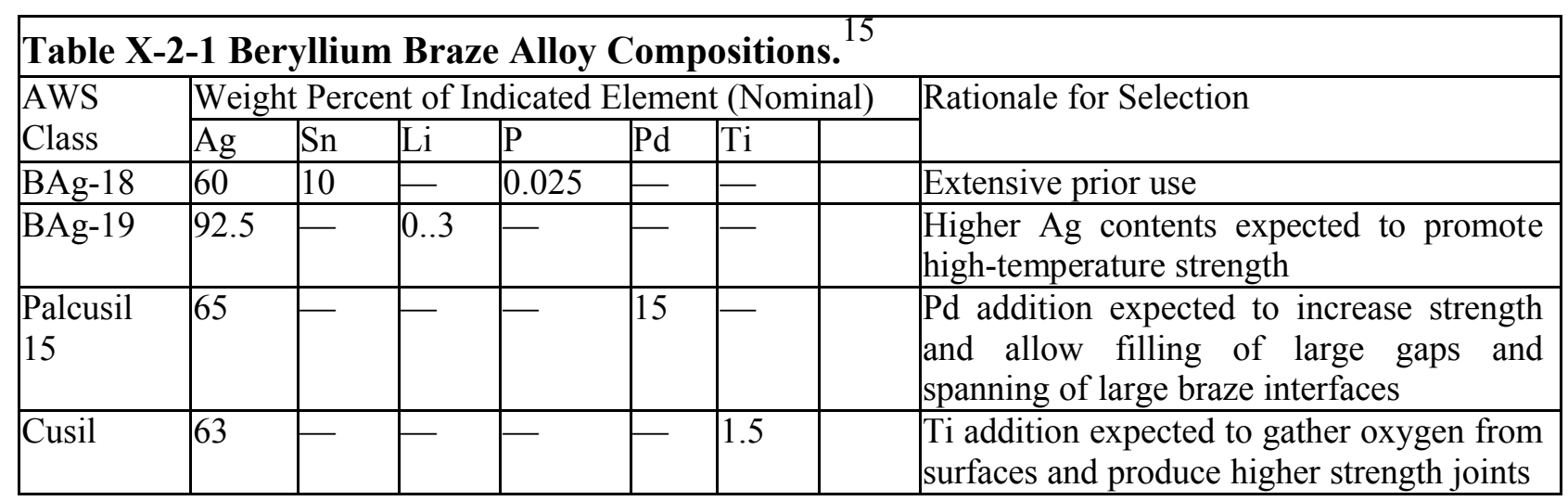


specimens brazed with this alloy frequently separated during final machining. Two of the alloys, BAg-18 and BAg-19, were further tested as compression panels. The results are shown in Fig. X2-6. BAg-18 was chosen over Pacusil-15 as its braze temperature had a much less degrading effect on the beryllium base metal. The mode of failure of the compression panels ranged from catastrophic brittle failure at lower temperatures to buckling at the higher temperatures.

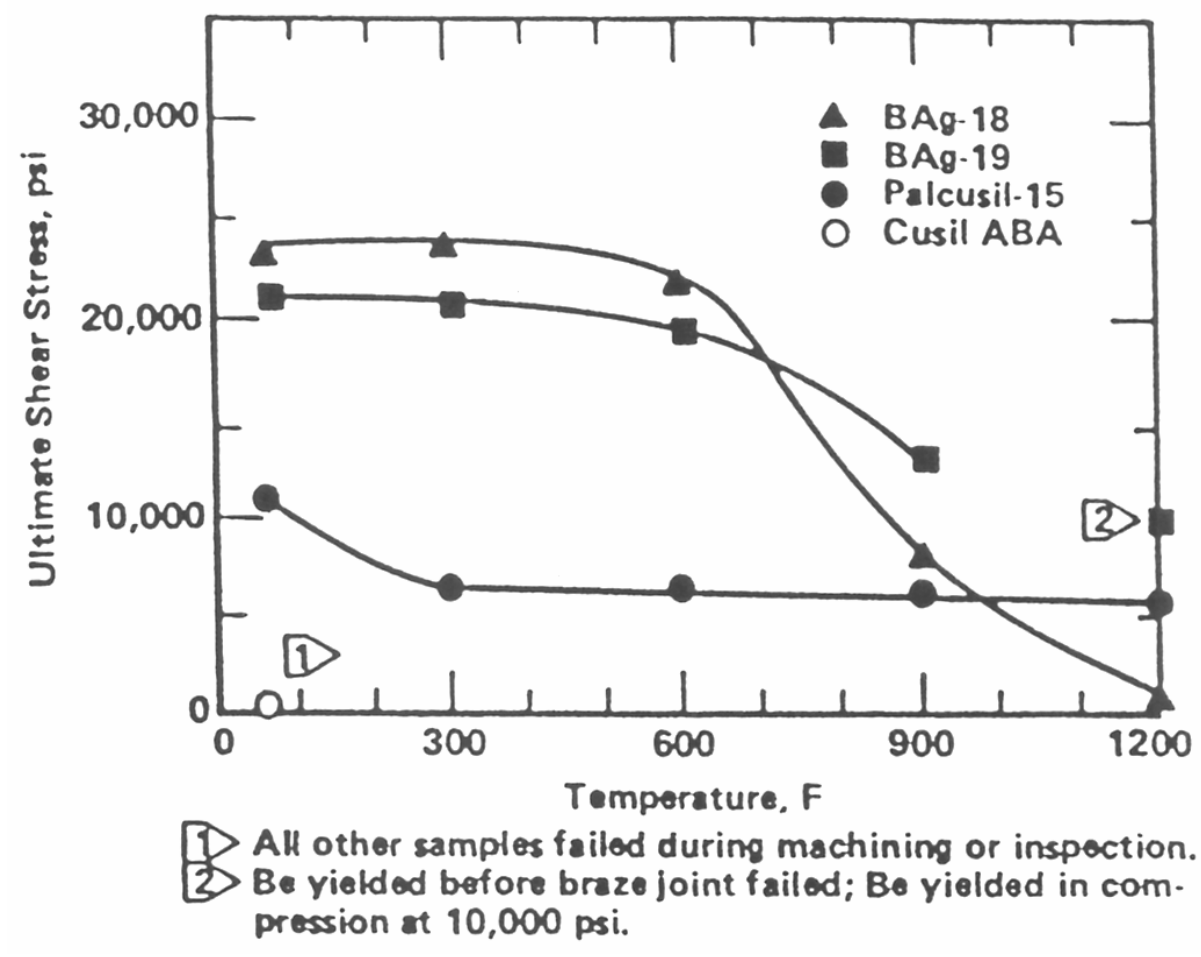

Fig. X-2-5 Ultimate shear stress versus test temperature for lap shear specimens of beryllium brazed to beryllium. 15

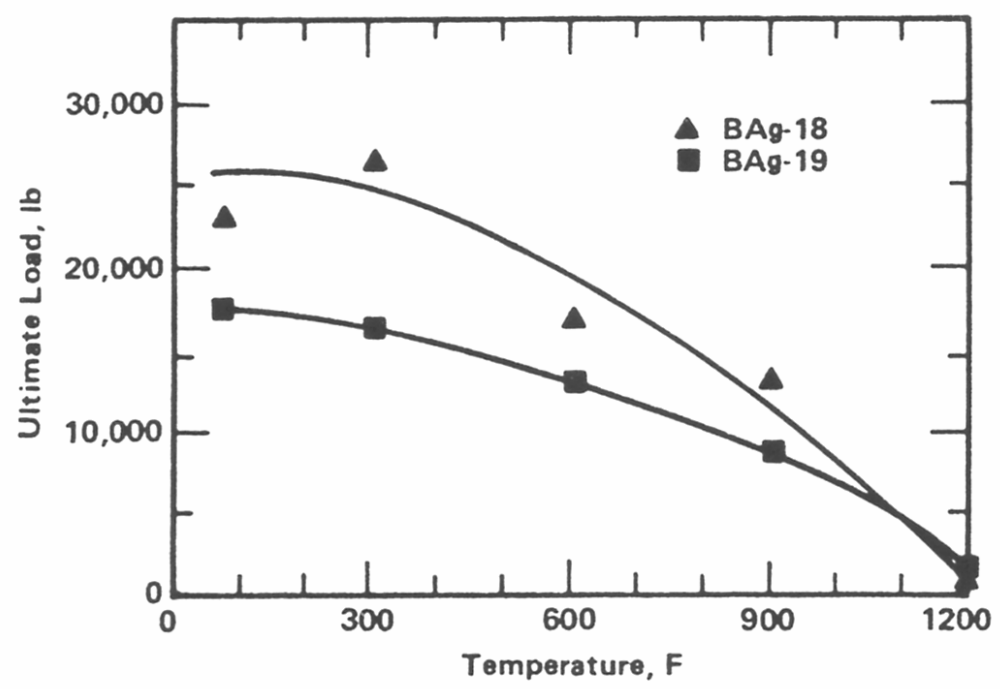

Fig. X-2-6 Results of compression-panel tests for two brazing alloys. ${ }^{15}$ 
An evaluation of silver brazing was performed by braze cladding a 50- $\mu$ m-thick foil of BAg-19 brazing alloy wrapped around a standard tensile bar, as depicted in Fig. X-2-7. Only minor differences were seen in the tensile properties between the as-received (hot-pressed) condition, following a brazing cycle only, and following the same brazing cycle that produced a brazed cladding. Results are given in Table X-2-2. ${ }^{14}$ In an attempt to avoid recrystallization by lowering the brazing temperature, a series of brazed beryllium specimens using a BAg-18 braze foil were made. Brazing was accomplished under a pressure of 1 to $3 \mathrm{kPa}$ over a range of temperatures from 590 to $760^{\circ} \mathrm{C}$ with times ranging from 2 to 45 minutes. Specimens were tested in single-lap shear. Optimum shear strengths ranging from 213 to $320 \mathrm{MPa}$ were achieved at a brazing temperature of about $650^{\circ} \mathrm{C}$. Metallographic evaluation of a parallel study with BAg-18 braze alloy showed that higher strength values and lesser times led to minimum intermetallic formation, whereas higher temperatures led to the formation of voids (Kirkendall voids ${ }^{\mathrm{bb}}$ ) and more intermetallics due to the presence of the copper in the braze alloy. ${ }^{14}$ This can be seen from Fig. X-2-8. A number of beryllium pin-and-base shear specimens (see Fig. X-2-9) with BAg-19 brazing alloy were brazed at $900^{\circ} \mathrm{C}$ for 10 minutes followed by either 0.5 or 3 hours at $760^{\circ} \mathrm{C}$. Brazed joints were made of several combinations of three different grades of beryllium using BAg-19 brazing alloy. The brazed joints showed considerable scatter, with no consistent trends. The shear values ranged between a low of $171 \mathrm{MPa}$ to a high of $301 \mathrm{MPa}$ with an average of $243 \mathrm{MPa}^{14}$

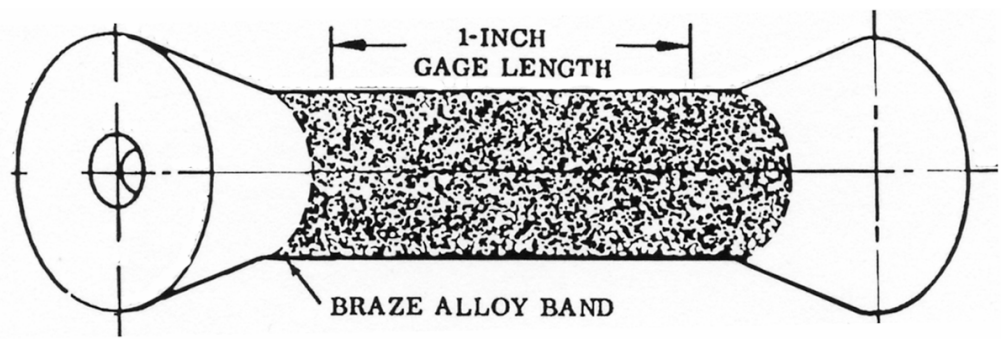

Fig. X-2-7 Standard round tensile bar for evaluating BAg-19 brazing-alloy foil that was braze-clad onto hot-pressed block beryllium. ${ }^{14}$

Aluminum-based brazing alloys are widely used fillers for brazing beryllium. Because of the lower brazing temperature that is used with these brazing alloys, the likelihood of recrystallization in beryllium, which occurs when brazing with silver-based alloys, is not a problem when brazing with aluminum-based alloys. The effect of brazing temperature, time, and joint gap on shear strength of beryllium-brazed specimens using an Al-Si eutectic alloy (Al-12\% $\mathrm{Si}$ ) is shown in Figs. X-2-10, X-2-11, and X-2-12, respectively. Cylinder/ring push specimens, as illustrated in Fig. X-2--13, were used. ${ }^{14}$ This design was adopted as it eliminated the tendency of the beryllium (due to its high modulus) to introduce a bending moment in conventional lap-shear specimens, which would

\footnotetext{
${ }^{\mathrm{bb}}$ Kirkendall effect originally described the movement of an interface between two different bonded materials due to the unequal rate of diffusion of atoms from each material across the interface. Thus one material had a net gain of atoms, while the other material lost atoms (mass) Similarly, the net microscopic movement of atoms locally can result in voids.
} 


\begin{tabular}{|c|c|c|c|}
\hline \multicolumn{4}{|c|}{$\begin{array}{l}\text { Table X-2-2. Surface-Braze-Test Results for BAg-19Brazing Alloy (50- } \mu \text {-Thick Foil) } \\
\text { Brazed Clad on Hot-Pressed Block (HPB) Beryllium. }\end{array}$} \\
\hline Condition $^{\mathrm{a}}$ & $\begin{array}{l}\text { Yield strength, } \\
\text { Mpa }\end{array}$ & $\begin{array}{c}\text { Tensile strength, } \\
\text { Mpa }\end{array}$ & $\begin{array}{l}\text { Elongation, } \% \\
\text { 25.4-mm gage }\end{array}$ \\
\hline As-received HPB (Hot-Pressed Be) & 254 & 308 & 1.2 \\
\hline As-received HPB & 267 & 347 & 2.7 \\
\hline Braze cycle only & 242 & 351 & 2.8 \\
\hline Braze cycle only & 239 & 320 & 1.7 \\
\hline Brazed with 6-mm band of BAg-19 foil & 244 & 337 & 2.0 \\
\hline Brazed with 6-mm band of BAg-19 foil & 240 & 311 & 6 \\
\hline Brazed with total band of BAg-19 foil & 245 & 333 & 7 \\
\hline Brazed with total band of BAg-19 foil & 222 & 373 & 8 \\
\hline
\end{tabular}

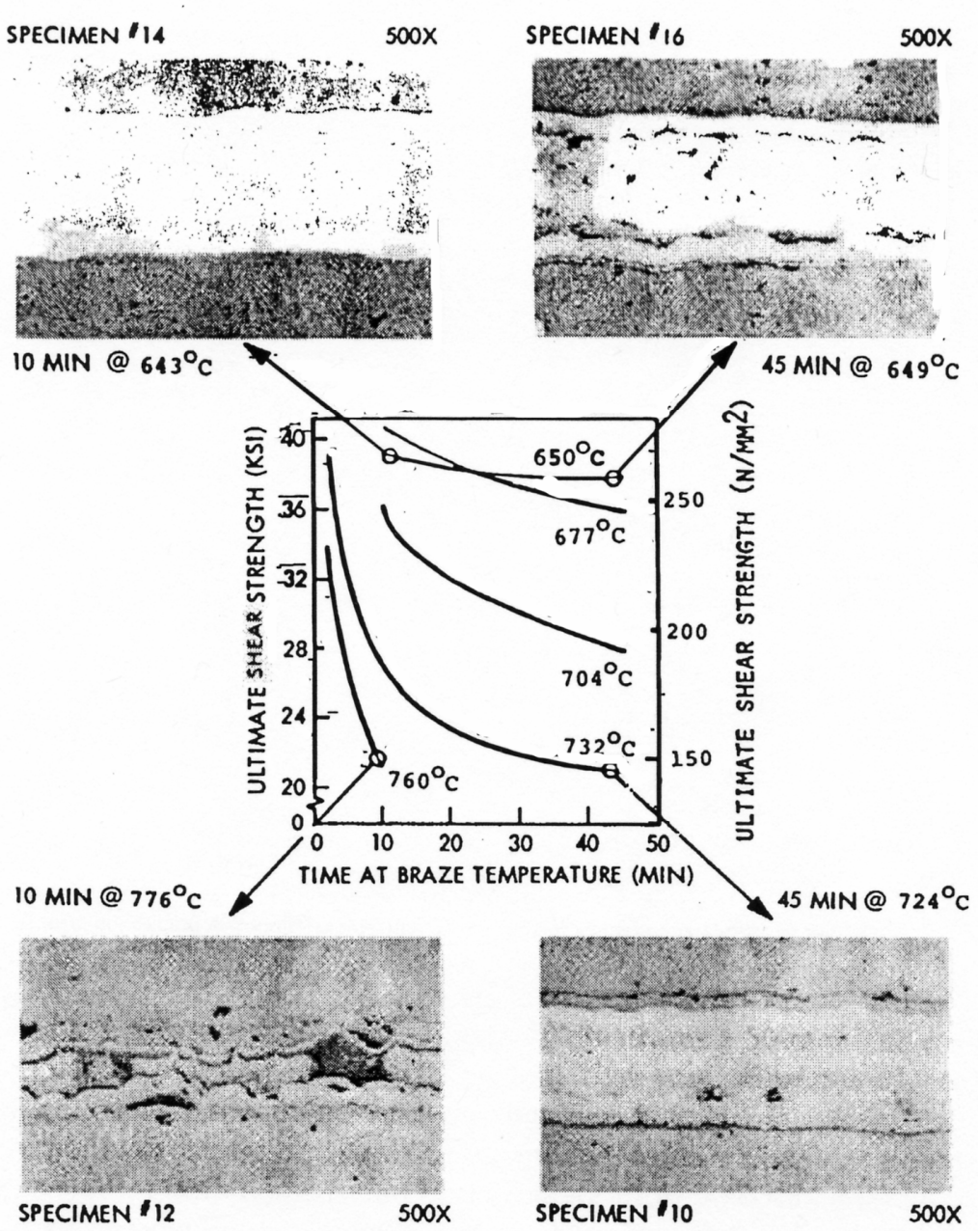

Fig. X-2-8 Effect of brazing temperature and time on strength and braze-joint microstructure of beryllium sheet brazed with BAg-18 alloy. (Mirostructures reproduced at approximately $50 \%$. $)^{14}$ 
distort pure shear values. The drop in shear strength with increasing temperature from about 20 to $200^{\circ} \mathrm{C}$ parallels the drop in tensile strength of annealed pure aluminum

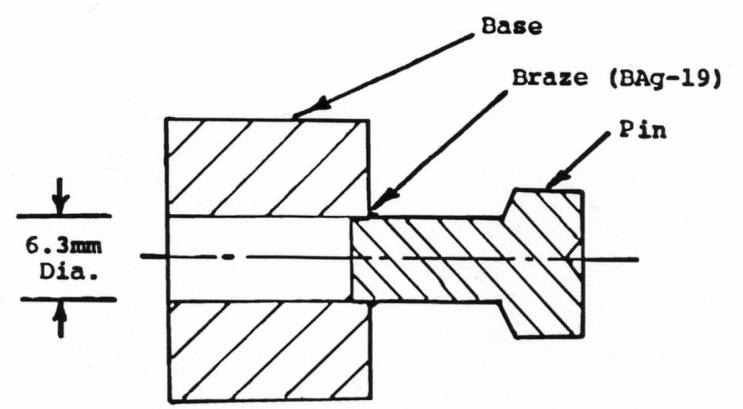

Fig. X-2-9 Base-and-Pin shear specimen used for testing BAg-19 brazing alloy. ${ }^{14}$

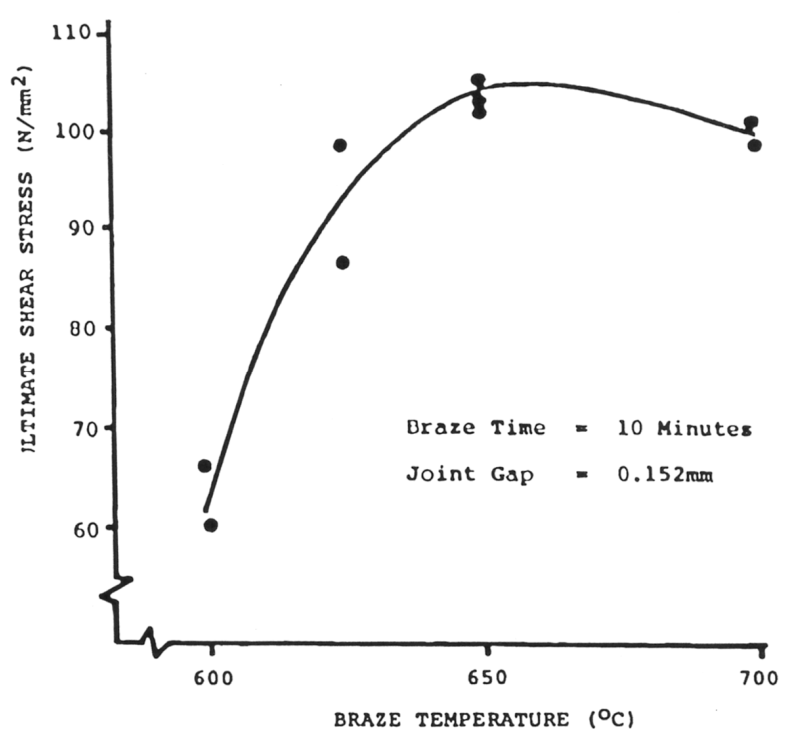

Fig. X-2-10 Shear strength versus brazing temperature for aluminum-brazed beryllium. ${ }^{14}$

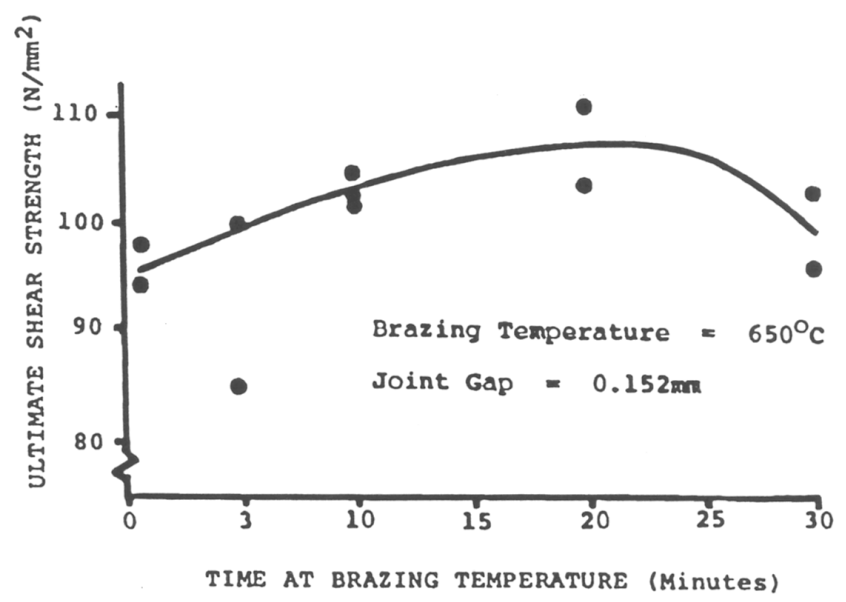

Fig. X-2-11 Shear strength as a function of time at brazing temperature for aluminumbrazed material. ${ }^{14}$ 


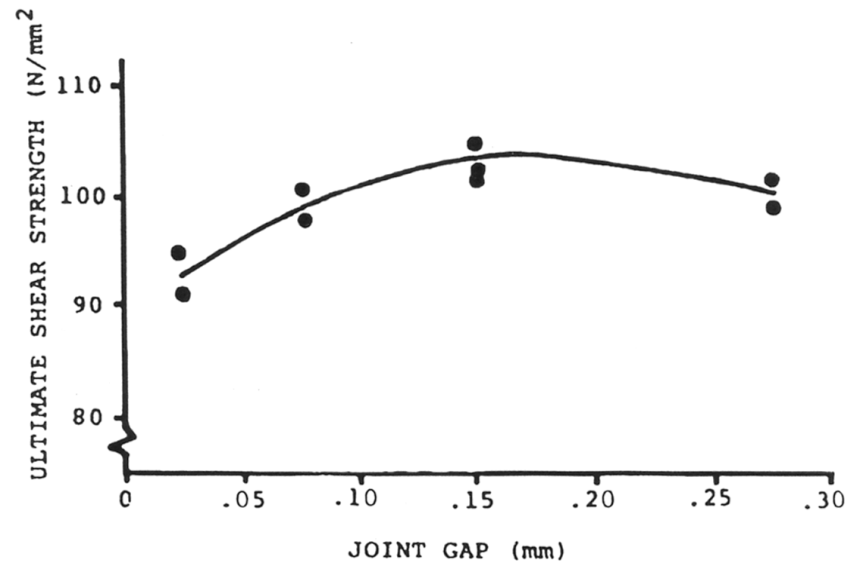

Fig. X-2-14 Shear strength as a function of joint gap for aluminum-brazed beryllium. ${ }^{14}$

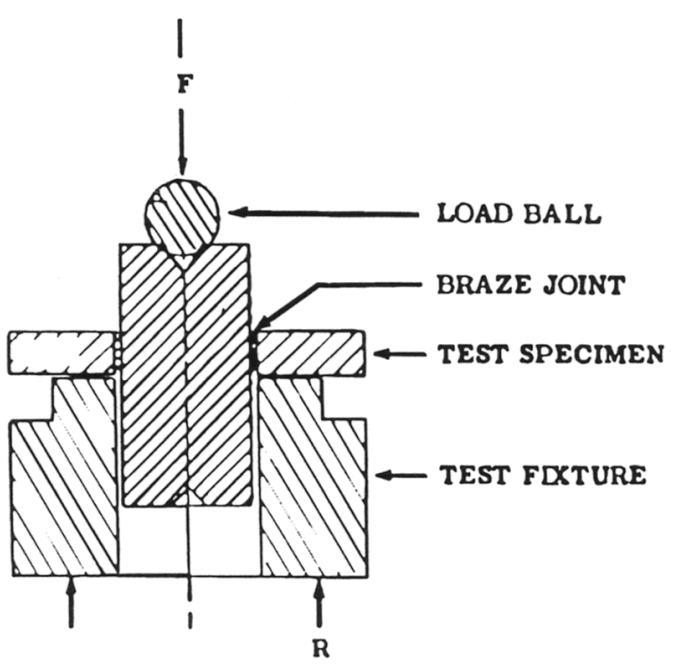

Fig.X-2-13 Schematic illustration of cylinder/ring push specimen and test fixture for shear testing of brazed joints. ${ }^{14}$

\section{X-3-Solid State Bonding}

\section{$\underline{\mathrm{X}-3-1-\text { Introduction }}$}

"Solid-state bonding" is a generic term that encompasses a number of closely related processes that are dependent on diffusion, pressure, and/or deformation to different degrees and that do not involve melting. At one extreme, in deformation bonding, the transport of material takes place by mechanical means and may not involve diffusion. Significant deformations are required to break up oxide films and sufficient pressures are required to cause fresh metal surfaces to come into contact and adhere between the fragmented oxides. Transfer of material across the interface between the two mating parts does not take place (this depends on deformation temperature) and the interface is usually clearly identifiable. At the other extreme, in diffusion bonding, bonding takes place by interdiffusion across the mating surfaces, possibly with grain growth across the 
boundary obscuring the original interface. The process is enhanced by some deformation, which occurs due to the applied pressure, as it aids in achieving contact between the two surfaces. Surfaces must be carefully prepared to assure maximum contact between mating surfaces and to minimize interference with the diffusion process. For example, deformation bonding can be insensitive to a rough surface, whereas diffusion bonding requires a clean, flat, microscopically smooth surface. Beryllium, being very reactive in ambient atmospheres, forming oxides and nitrides, should be joined under vacuum when possible. In not involving any liquid phase and also being performed at temperatures lower than those attained in the fusion processes, solid-state processes, especially those that do not involve any significant amount of deformation, have a number of advantages over other joining processes:

- mechanical properties approaching base-metal properties

- reduced joining temperatures

- minimum (or no) grain growth, depending on temperature

- absence of cast structures

- limited distortion

- numerous welds can be made simultaneously

- bonding ability is largely independent of part thickness

- weight reduction relative to that obtained when using fillers

- better heat transfer relative to that obtained when using fillers

- possibility of joining and heat treating simultaneously.

- more flexibility in joint design

- less fixturing relative to that required in fusion processes.

Some disadvantages may exist for processes in which the bonding relies mainly on diffusion:

- long process times may be required

- increase in temperature to shorten time may cause excessive creep

- increase in temperature to shorten time may induce undesirable microstructural changes

- increases in heat and pressure requirements may increase costs

Numerous solid-state bonding processes are available; some are referred to by different names and the terms welding and bonding have been used interchangeably. Some examples are given below:

- gas-pressure bonding - a diffusion process utilizing pressurized gas

- press bonding - joining pressure is applied by a press

- pressure bonding - generic for any method that uses pressure to complete the bonding process

- vacuum bonding - joining performed in a vacuum

- forge welding - application of heat and pressure using a forging press

- roll bonding - deformation bonding by rolling

- explosive bonding - deformation bonding induced by shock waves

- cold welding - pressure is used to initiate the bond

- differential-thermal expansion(DTE) bonding - pressure induced by DTE of the different materials, either between mating parts or parts and fixture 


\section{$\underline{X-3-2-B o n d i n g ~ M e c h a n i s m s ~}$}

Diffusion bonding can be achieved by either having the work pieces in direct contact with each other or by having a very thin intermediate metal layer between the work pieces. In both cases, at times referred to as "direct diffusion bonding" and "indirect diffusion bonding," respectively, the joint is heated to an elevated temperature and placed under pressure. Heating-cycle times for processes can run from four to five hours with at least one half hour at the maximum temperature. Temperatures typically range from 815 to nearly $1100^{\circ} \mathrm{C}$ with bonding pressures from about 35 to $70 \mathrm{MPa}$. Applied loads are usually considerable greater for the indirect process as compared to those used in the direct process. In both cases, mating surfaces must be clean and flat. A flatness of better than a half wave length of light $(0.3 \mu \mathrm{m}$ interference) is generally recommended, especially for the direct-diffusion process. Surface perturbations or lack of flatness can result in uneven bonding due to non-uniform pressures along the interfaces at the bonding temperature. An intermediate soft-metal layer assures cleanliness as well as reducing problems due to surface asperities. The intermediate layer can also improve joint strength. In addition to cleanliness, the oxide film normally present on beryllium (or on any other reactive metal being bonded) must first be removed (or penetrated) before interdiffusion can take place between the metals in contact. Oxides can be removed to a large degree by abrasion or etching. The shearing deformation that occurs on the application of pressure during the solid-state-diffusion process aids in furthering the breakup of the oxide films. It has been demonstrated that there is an optimum microscopic roughness for the most effective oxide breakdown. Furthermore, surfaces bonded at an angle to the load produced stronger bonds than those bonded normal to the load, especially for small deformations. ${ }^{16}$ In heating up the work pieces, care is taken that the elastic limit is not exceeded during heating. Typically, only a light load is initially applied, which may be monitored (and even lowered) during heating; the required bonding load is then applied on reaching the bonding temperature.

Several mechanisms have been proposed for the bonding process. ${ }^{16}$ In one proposal, the stress resulting from the pile-up of dislocations at the metal-oxide interface, and favorably oriented for plastic flow, causes cracking of the oxide film with corresponding exposures of the bare metal. Where cracking and breakup of the oxide occur on both sides of the interface, forming gaps where both bare metals are in contact, plastic flow occurs across these gaps providing intimate contact for diffusion. In another proposal it is suggested that the bonding process occurs by void formation followed by void shrinkage, which is illustrated in Fig. X-3-1. Initially, the applied pressure produces interface regions of intimate contact and irregular-shaped voids. The drive for minimization of surface-free energy results in the voids tending towards a spherical shape through volume and surface diffusion. With time, these voids will shrink and disappear. Generally, the greater the roughness of the surfaces, the longer the time required for the bonding process.

It was suggested that direct-diffusion bonding requires temperatures of the order of $1120^{\circ} \mathrm{C}$ and loaded stresses of about $10 \mathrm{kPa} .{ }^{12}$ Olson and Liby ${ }^{16}$ stated, however, that clean beryllium surfaces may be bonded together at temperatures as low as $700^{\circ} \mathrm{C}$, provided that the bonding time and pressure are sufficient. Bonds made at temperatures above $1000^{\circ} \mathrm{C}$ may suffer a loss of properties due to excessive grain growth. Furthermore, a high $\mathrm{BeO}$ content may interfere with the bonding 
process, and other impurities may influence bonding through precipitation reactions. Since diffusion rates increase exponentially with temperature, bonding times could be correspondingly reduced with increasing temperatures. If an intermediate metal is used between the beryllium parts, the maximum temperature would be limited by the possibility of forming undesirable intermetallics or a low-temperature liquid phase; e. g., the Ag-Be and Al-Be phase diagrams exhibit eutectic liquid at 881 and $645^{\circ} \mathrm{C}$, respectively.
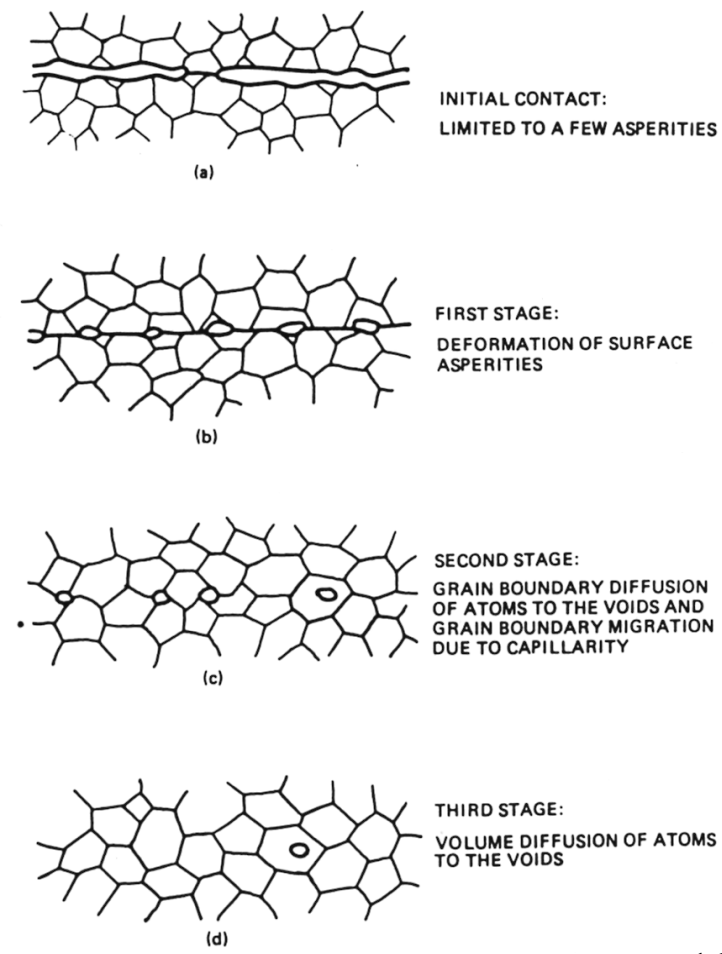

Fig. X-3-1 Schematic of proposed stages of solid-state bonding. ${ }^{16}$

Results obtained by a number of investigators on direct-diffusion bonding of beryllium are summarized in Table X-3-1. ${ }^{16}$ In their paper, the authors ${ }^{16}$ reviewed the results obtained by several of these investigators. Some of the details are presented in the following discussion.

Passmore obtained bonding of both hot-pressed and extruded QMV grade Be with surfaces that were metallographically polished; some surfaces were only finish ground on 180-grit paper. Highstrength bonds were obtained with the polished specimens even though very little plastic deformation or disruption of the original surfaces was observed on the fractured surfaces. Maximum strengths were obtained by bonding in the range of 900 to $1000^{\circ} \mathrm{C}$. The lower bond strengths were attributed to the lower diffusion rates and the higher material yield strengths at the lower bonding temperatures and to recrystallization at the higher bonding temperatures. 


\begin{tabular}{|c|c|c|c|c|c|c|c|c|}
\hline Table X-3- & Direct-Diff & fusion & onding of & Beryll & um (pri & r to 1979) & & \\
\hline & & Bondin & Conditions & & & & & \\
\hline Investigators & Material & $\begin{array}{l}\text { Temp, } \\
{ }^{{ }^{C} \mathrm{C}}\end{array}$ & $\begin{array}{l}\text { Pressure, } \\
\mathrm{MPa}\end{array}$ & $\begin{array}{l}\text { Time, } \\
\text { hours }\end{array}$ & $\begin{array}{l}\text { Atmos- } \\
\text { phere }\end{array}$ & $\begin{array}{l}\text { Maximum } \\
\text { strength, } \\
\text { MPa }\end{array}$ & Comments & Ref. $^{\mathrm{a}}$ \\
\hline Martin & $\mathrm{Be}$ & $\begin{array}{l}900- \\
1200\end{array}$ & Contact & 2.5 & Vacuum & 193 & $\begin{array}{l}\text { Found transinterfacial } \\
\text { grain growth }\end{array}$ & 3 \\
\hline Atkins & $\mathrm{Be}$ & $\begin{array}{l}200- \\
800\end{array}$ & $\begin{array}{l}\text { Above } \\
\text { yield }\end{array}$ & & Argon & 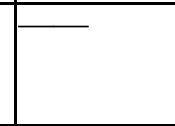 & $\begin{array}{l}\text { Determined temperature- } \\
\text { deformation curve for } \\
\text { bonding beryllium }\end{array}$ & 3 \\
\hline Monroe & $\mathrm{Be}$ & 850 & 20.7 & 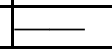 & 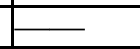 & 275 & Butt-welded rods & 3 \\
\hline D’Annessa & $\mathrm{Be}$ & 885 & 13.8 & 0.25 & Vacuum & 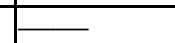 & 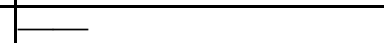 & 5 \\
\hline $\begin{array}{l}\text { Batzer and } \\
\text { Bunshah }\end{array}$ & $\begin{array}{l}\text { Be with } \\
2 \% \mathrm{BeO}\end{array}$ & $\begin{array}{l}200- \\
400\end{array}$ & $\begin{array}{l}27.6 \text { to } \\
103\end{array}$ & 1 & Vacuum & 51 & $\begin{array}{l}\text { Ion bombardment } \\
\text { surface cleaning }\end{array}$ & 6 \\
\hline $\begin{array}{l}\text { Hodge, } \\
\text { et. al. }\end{array}$ & $\mathrm{Be}$ & $\begin{array}{l}843 \\
954\end{array}$ & 69 & $\begin{array}{l}2 \text { to } \\
4\end{array}$ & Air & 251 & Surface treatment only & 7 \\
\hline Bosworth & $\begin{array}{l}\text { SR-200D } \\
\text { PR-200D }\end{array}$ & $\begin{array}{l}730- \\
790\end{array}$ & 10.4 & $\begin{array}{l}3 \text { to } \\
6\end{array}$ & Vacuum & $\begin{array}{l}379 \\
\text { shear }\end{array}$ & $\begin{array}{l}\text { Studied role of micro- } \\
\text { alloying elements }\end{array}$ & $\begin{array}{l}15 \\
16 \\
\end{array}$ \\
\hline $\begin{array}{l}\text { Hauser, } \\
\text { et. al. }\end{array}$ & $\begin{array}{l}\mathrm{Be}+1-1.7 \\
\% \mathrm{BeO}\end{array}$ & $\begin{array}{l}750- \\
850\end{array}$ & $\begin{array}{l}7 \text { to } \\
100\end{array}$ & $\begin{array}{l}1 \text { to } \\
12\end{array}$ & Vacuum & 427 & - & 17 \\
\hline Albom & $\mathrm{Be}$ & $\begin{array}{l}800- \\
1500\end{array}$ & ------ & 1 & Vacuum & $\bar{\square}$ & $\begin{array}{l}100 \% \text { joint efficiencies } \\
\text { have been achieved in } \\
\text { butt joints }\end{array}$ & 1 \\
\hline Passmore & $\begin{array}{l}\text { QMV hot- } \\
\text { pressed Be }\end{array}$ & $\begin{array}{l}800- \\
1150\end{array}$ & $\begin{array}{l}\text { Above } \\
\text { yield }\end{array}$ & 1 & Vacuum & 275 & $\begin{array}{l}\text { Specimens were loaded } \\
\text { by thermal expansion }\end{array}$ & 4 \\
\hline Passmore & $\begin{array}{l}\text { QMV } \\
\text { extruded Be }\end{array}$ & $\begin{array}{l}800- \\
1150\end{array}$ & $\begin{array}{l}\text { Above } \\
\text { yield }\end{array}$ & 1 & Vacuum & 414 & $\begin{array}{l}\text { difference between Mo } \\
\text { clamps and Be }\end{array}$ & \\
\hline
\end{tabular}

Parent-metal strengths following solid-state bonding were obtained by Hodge etal. ${ }^{16}$ The bonding was accomplished by sealing the assembled components in an evacuated expandable container, which was then placed into a high-pressure autoclave. The container was then subjected to isostatic pressure using an inert gas. Optimum bonding was obtained at $850^{\circ} \mathrm{C}$ for four hours. Tests were formed at temperatures of 843 to $954{ }^{\circ} \mathrm{C}$ for two to four hours. Prior blasting the surfaces with chilled iron grit enhanced the bonding. The localized deformation introduced by the blasting promoted recrystallization at and grain growth across the interface.

The studies performed by Hauser et al ${ }^{19}$. were on beryllium sheet containing 0.97 and 1.70 wt.\% $\mathrm{BeO}$. Surface preparation was limited to chemical etching. Bond strengths exceeding $90 \%$ of the base-metal properties at room temperature were obtained for the low-oxide material by bonding in the temperature range of 760 to $780^{\circ} \mathrm{C}$ for three hours under a pressure of $10.3 \mathrm{MPa}$. Such results were not achieved with the high oxide material. In joining sheet material, the bond strength is influenced by the sheet thicknesses and their impurity content, especially $\mathrm{BeO}$.

\section{$\underline{\mathrm{X}-3-3 \text { - Intermediate Layers (Indirect Bonding) }}$}

An intermediate metal layer may be used to provide a clean mating surface as well as to reduce the effects of surface asperities. Nickel, gold, and silver are the main metals that are used for such 
purposes. Copper and alloy foils have also been used successfully The intermediate layer may either be deposited on the beryllium mating surfaces or be placed between the two surfaces. Silver-coated beryllium bonds usually produce excellent joints with the failure most often occurring along the silver-silver interface. Silver, which does not form a very stable oxide, can be deposited on the beryllium by either electroplating or vacuum evaporation (deposition), with either electron-beam evaporation or magnetron-sputtering evaporation being the two techniques most commonly used. Hot-hollow-cathode sputtering evaporation, which had previously been widely used in large-scale production is less common now. With the latter technique, relatively thick deposits were formed, which were subsequently reduced to the desired thickness by machining. Machining stresses might be eliminated by annealing prior to bonding. Beryllium tensile specimens bonded using electrodeposited silver have achieved strengths as high as $441 \mathrm{MPa}$ with fracture occurring in the beryllium rather than in the joint. ${ }^{16}$

Where a thin separate layer is bonded to the beryllium, and is uniaxially loaded normal to the plane of the bond, the layer behaves mechanically similarly to the beryllium in the elastic range of the beryllium. Because of the triaxial-stress state developed in the thin layer, the layer is prevented by the beryllium from contracting (deforming) in the direction normal to the loading axis, even though the layer material may have a lower yield strength than the beryllium. Subsequent relaxation, which is due to the loss of stress triaxiality as beryllium yields, limits the joint strength, and fracture may occur in the layer. The same constraints may develop with a deposited layer

\begin{tabular}{|c|c|c|c|c|c|c|c|c|c|}
\hline Table $\mathrm{X}$ - & 3-2 Diffu & ion Bor & ing of & rylliur & with Int & mediate & ayer. $^{16}$ & & \\
\hline & & Bondin & Conditi & & & Inter- & Max & & \\
\hline $\begin{array}{l}\text { Investi- } \\
\text { gators }\end{array}$ & Material & $\begin{array}{l}\text { Temp } \\
{ }^{{ }^{C} \mathrm{C}}\end{array}$ & $\begin{array}{l}\text { Press } \\
\mathrm{MPa}\end{array}$ & $\begin{array}{l}\text { Time } \\
\text { hour }\end{array}$ & $\begin{array}{l}\text { Atmos- } \\
\text { phere }\end{array}$ & $\begin{array}{l}\text { mediate } \\
\text { layer }\end{array}$ & $\begin{array}{l}\text { strength } \\
\mathrm{MPa}\end{array}$ & Comments & $\operatorname{Ref}^{\mathrm{a}}$ \\
\hline $\begin{array}{l}\text { Hauser } \\
\text { Howden } \\
\text { Monroe }\end{array}$ & $\begin{array}{l}\text { Be with } \\
1 \text { to } 2 \% \\
\text { BeO }\end{array}$ & 800 & $\begin{array}{l}17 \text { to } \\
32\end{array}$ & 4 to 6 & Vacuum & $\begin{array}{l}\text { Al, } \\
\text { Al-Si }\end{array}$ & 207 & $\begin{array}{l}\text { Al intermediate } \\
\text { foils did not } \\
\text { assist bonding }\end{array}$ & 17 \\
\hline $\begin{array}{l}\text { Hauser } \\
\text { Howden } \\
\text { Monroe }\end{array}$ & $\begin{array}{l}\text { Be with } \\
1 \text { to } 2 \% \\
\text { BeO }\end{array}$ & & & & Vacuum & $\begin{array}{l}\mathrm{Ni} \\
\mathrm{Ni}-\mathrm{Cu}\end{array}$ & brittle & $\begin{array}{l}\mathrm{Ni} \text { and } \mathrm{Cu}-\mathrm{Ni} \\
\text { foils resulted in } \\
\text { brittle joints }\end{array}$ & 17 \\
\hline $\begin{array}{l}\text { Knowles } \\
\text { Hazlett }\end{array}$ & S-200C & $\begin{array}{l}107 \text { to } \\
199\end{array}$ & 29 & $\begin{array}{l}0.008 \\
\text { to } \\
4\end{array}$ & $\begin{array}{l}\text { Vacuum } \\
\text { helium } \\
\text { oxygen }\end{array}$ & $\mathrm{Ag}$ & 275 & $\begin{array}{l}\text { Strength not a } \\
\text { strong function } \\
\text { of environment }\end{array}$ & 8 \\
\hline $\begin{array}{l}\text { O'Brian } \\
\text { Rice } \\
\text { Olson }\end{array}$ & S-200E & 200 & 138 & 0.167 & Air & $\mathrm{Ag}$ & 434 & $\begin{array}{l}\text { Electroplated } \\
\text { and vapor- } \\
\text { deposited silver } \\
\text { were both used }\end{array}$ & 22 \\
\hline \begin{tabular}{|l|} 
Naimon \\
Vigil \\
Villegas \\
Williams \\
\end{tabular} & S-200E & 200 & 138 & 0.167 & Air & Ag & 324 & $\begin{array}{l}\text { Study made of } \\
\text { ion bombard- } \\
\text { ment cleaning } \\
\text { prior to coating }\end{array}$ & 24 \\
\hline
\end{tabular}


The thinner the layer, the greater and more effective are the constraints. Table X-3-2 lists the results of a number of investigators experimenting with bonding beryllium using intermediate layers. ${ }^{16}$ In their paper, the authors ${ }^{16}$ reviewed the results obtained by several of these investigators. Some of the details are presented in the following discussion.

Knowles and Hazlett were the first to demonstrate the use of silver for solid-state bonding at relatively low temperatures. They bonded S-200C beryllium, plated with a $12.7-\mu \mathrm{m}$-thick layer of silver, at $107^{\circ} \mathrm{C}$ under a bonding pressure of $207 \mathrm{MPa}$ and obtained a bond strength of $120 \mathrm{MPa} .{ }^{17}$ They noted that over the bonding-temperature range of 107 to $138^{\circ} \mathrm{C}$ the bond strengths were insensitive to the environment, either vacuum $\left(10^{-6}\right.$ torr $)$, helium, air, or oxygen. They also noted that the bond strength increased linearly with the plated-silver thickness with thicknesses ranging from 14.7 to $76 \mu \mathrm{m}$. (The relationship also held for samples bonded at $204^{\circ} \mathrm{C}$.) This is contrary to the effect normally obtained, namely, that the triaxiality increases and thus also the strength with decreasing thickness of the interlayer. They attributed this contradiction to the increase in contact area obtained with increasing interlayer thickness. The start of a rapid increase in bond strength with increasing bonding stress that occurred after plastic strain was initiated was observed. This was attributed to a corresponding increase in bond area with an increase in plastic strain. ${ }^{17}$ The plastic strain of the sample was measured adjacent to the bond. Higher bond strengths were obtained by maintaining the bonding stress while cooling to room temperature. It should be pointed out that the above results refer to relatively lowtemperature bonding. The authors conclude that the bonding at these low temperatures occurred largely by cohesion (atomic bonding forces between surfaces in contact) rather than by diffusion. The limited role of diffusion was supported by the independence of bond strength on the time at the bonding temperature; the cohesion concept was supported by a linear relationship between bond strength and bonding pressure. ${ }^{17}$

O'Brien etal. found that the bond strength of a Ag-Ag solid-state bond can be as high as $690 \mathrm{MPa}$ (about double the strength of $\mathrm{Be}$ ). ${ }^{16}$ This result was obtained by tensile testing solid-state bonded, silver-coated, high-strength maraging steel to assure that failure would occur at a silver interface. They also noted that the strength of the joint increased with decreasing joint thickness due to the increased constraint. With extremely thin layers, however, the strength can be reduced due to surface roughness and lack of cleanliness hindering contact area. In contrast to the successful bonding obtained at $107^{\circ} \mathrm{C}$ reported above, O'Brien etal. found that the strength of silver bonds was drastically reduced for bonding temperatures below $150^{\circ} \mathrm{C}$. At a $400^{\circ} \mathrm{C}$ bonding temperature, they obtained similar bond strengths for either a one- or ten-minute period suggesting that the bonding kinetics are extremely fast at this temperature. They also reported that a threshold bonding pressure was required to obtain an acceptable bond, with no improvement above this pressure (e. g., $69 \mathrm{MPa}$ at $200^{\circ} \mathrm{C}$ ). Too high a pressure can reduce the bond strength due to edge deformation, which results in a reduction of contact area. As can be seen from the Ag-Be phase diagram in Fig. X-3-2, bonding temperatures should be kept below $760^{\circ} \mathrm{C}$ for fear of introducing the intermetallic delta $(\delta)$ phase, $\mathrm{AgBe}_{2}$. 


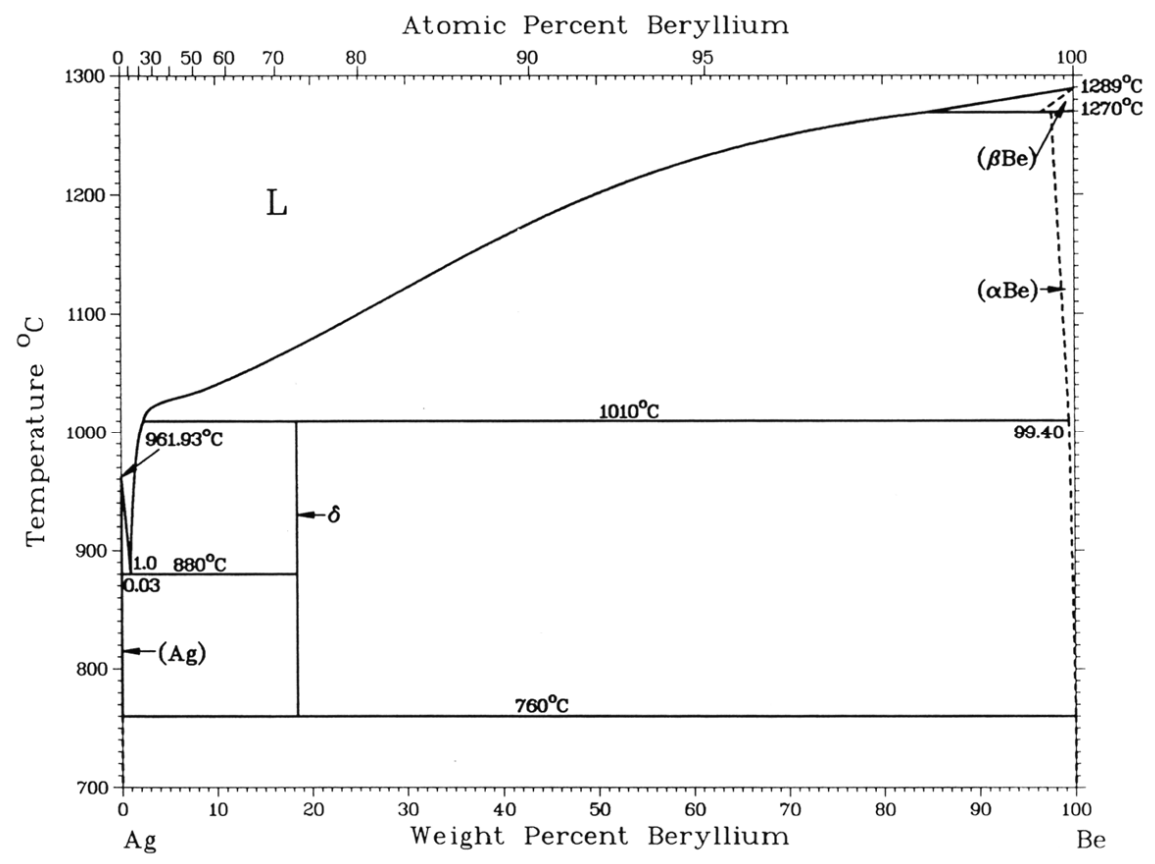

Fig. X-3-2 Silver-beryllium phase diagram ${ }^{18}$

\section{$\underline{X-3-4-S u r f a c e ~ P r e p a r a t i o n ~}$}

Adhesion of the silver coating to the beryllium substrate is essential for achieving reliable bonding. In studies using a hollow cathode source, the adhesion of the silver coating was found to be a function of the substrate current and bias. Lower currents and voltage levels may result in weaker adhesion of the silver to the beryllium. The importance of surface cleanliness prior to coating is illustrated in Fig. X-3-3, which shows the effect of cleaning energy used on bond strength during the ion-bombardment-cleaning stage when using the hot-hollow-cathode sputtering-evaporation process. 16

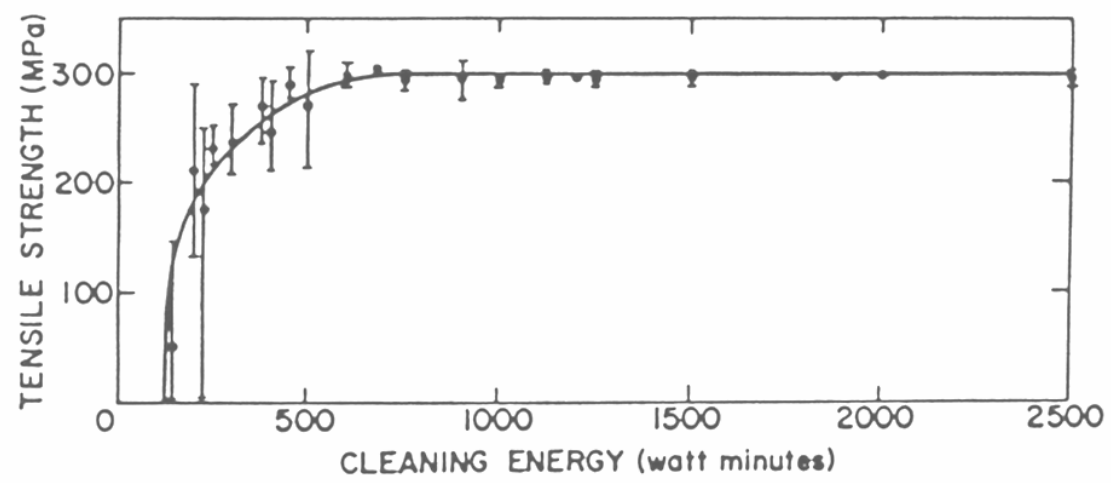

Fig. X-3-3 Silver solid-state-bond strength as a function of total energy used for cleaning by ion bombardment prior to silver deposition. ${ }^{16}$ 


\begin{tabular}{|c|c|c|c|c|c|c|c|}
\hline Investigator & Grinding & Polishing & Cleaning & Etching & Inspection & Comments & $\operatorname{Ref}^{a}$ \\
\hline Passmore & $\begin{array}{l}\text { Wet SiC } \\
\text { paper }\end{array}$ & $\begin{array}{l}\text { cloth laps with } \\
\text { levigated } \\
\text { alumina in dilute } \\
\text { oxalic acid }\end{array}$ & $\begin{array}{l}\text { Volatile } \\
\text { solvents }\end{array}$ & & & & 4 \\
\hline $\begin{array}{l}\text { Hodge } \\
\text { etal. }\end{array}$ & \begin{tabular}{|l} 
Both \\
machined \\
and abraided \\
surfaces
\end{tabular} & & & $\begin{array}{l}\text { Dilute } \mathrm{H}_{2} \mathrm{SO}_{4}, \\
\text { Dilute } \mathrm{HNO}_{3-} \\
\mathrm{HF} \text {, or } \\
\mathrm{H}_{3} \mathrm{PO}_{4}-\mathrm{CO}_{3}\end{array}$ & & $\begin{array}{l}10 \% \mathrm{H}_{2} \mathrm{SO}_{4} \\
\text { appeared to be the } \\
\text { best }\end{array}$ & 7 \\
\hline Hodge et al & Grit blasting & 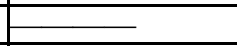 & 年 & Dilute $\mathrm{HNO}_{3}$ & $\bar{z}$ & Promising & 7 \\
\hline Bosworth & $\begin{array}{l}\text { Machined } \\
\text { and ground }\end{array}$ & & $\begin{array}{l}\text { Etch followed by } \\
\text { hot-water rinse }\end{array}$ & $\begin{array}{l}40 \% \mathrm{HNO}_{3}+ \\
5 \% \mathrm{HF} \text { at } \\
\text { room temp. }\end{array}$ & & $\begin{array}{l}\text { Etch to remove } 20 \\
\text { to } 25 \mu \mathrm{m} \text { from } \\
\text { surfaces. Cleaned } \\
\text { specimen remained } \\
\text { exposed to shop } \\
\text { atmosphere for } 45 \\
\text { minutes before } \\
\text { insertion into } \\
\text { vacuum chamber }\end{array}$ & $\begin{array}{l}15, \\
16\end{array}$ \\
\hline Albom & $\begin{array}{l}\text { Wet SiC } \\
\text { paper }\end{array}$ & $\begin{array}{l}\text { levigated } \mathrm{Al} \text { in } \\
\text { dilute oxalic } \\
\text { acid }\end{array}$ & & & & $\begin{array}{l}\text { Chemical etch } \\
\text { Gave matte } \\
\text { surface, which was }\end{array}$ & \\
\hline Albom & $\begin{array}{l}\text { No. } 1 \text { gut } \\
\text { emery paper }\end{array}$ & & $\begin{array}{l}\text { Acetone, } \\
\text { at times followed } \\
\text { with ether }\end{array}$ & & & $\begin{array}{l}\text { not conducive to } \\
\text { satisfactory } \\
\text { bonding }\end{array}$ & 1 \\
\hline Hauser etal. & 600-gritpaper & & $\begin{array}{l}\text { Rinse in tap water } \\
\text { plus } \\
\text { acetone }\end{array}$ & $\begin{array}{l}40 \mathrm{HNO}_{3}-2 \mathrm{HF}- \\
58 \mathrm{H}_{2} \mathrm{O} \text { in wt. } \%\end{array}$ & & $\begin{array}{l}1 \text { hour between } \\
\text { cleaning and } \\
\text { bonding }\end{array}$ & 17 \\
\hline $\begin{array}{l}\text { Knowles } \\
\text { and } \\
\text { Hazlett }\end{array}$ & Ground flat & $\begin{array}{l}\text { Hand polish } \\
\text { with alumina } \\
\text { and lap on thick } \\
\text { to } 0.5 \mu \mathrm{m} \\
\text { abrasive or } \\
\text { bonding surface } \\
\end{array}$ & $\begin{array}{l}\text { Cotton swab with } \\
\text { acetone followed by } \\
\text { low-power } \\
\text { ultrasonic cleaning } \\
\text { in acetone for } 0.157 \\
\text { hours }\end{array}$ & & $\begin{array}{l}\text { Surface } \\
\text { finish on } \\
\text { bond surface } \\
\text { of } \\
\text { 2rms }\end{array}$ & $\begin{array}{l}\text { Procedure used for } \\
\text { preparing } \\
\text { specimens } \\
\text { for silver-coating } \\
\text { procedures }\end{array}$ & 8 \\
\hline $\begin{array}{l}\text { O'Brian } \\
\text { etal. }\end{array}$ & $\begin{array}{l}\text { Lapping } \\
\text { machine with } \\
3 \mu \mathrm{m} \text { alumina } \\
\text { and light oil }\end{array}$ & & $\begin{array}{l}\text { Ultrasonic wash for } \\
5 \text { min in } 3 \% \text { Oakite } \\
\text { NST aluminum- } \\
\text { detergent-distilled } \\
\mathrm{H}_{2} \mathrm{O} \text { solution, } \\
\text { followed by } 3 \text { to } 5 \\
\text { min ultrasonic } \\
\text { cleaning in distilled } \\
\mathrm{H}_{2} \mathrm{O}\end{array}$ & & $\begin{array}{l}\text { Flat to one } \\
\text { light } \\
\text { band after } 20 \\
\text { min of } \\
\text { lapping. } \\
\text { Used Auger } \\
\text { analysis to } \\
\text { determine } \\
\text { contamin- } \\
\text { ation level }\end{array}$ & $\begin{array}{l}\text { Procedure for } \\
\text { preparing surfaces } \\
\text { for silver } \\
\text { deposition } \\
\text { procedures; also } \\
\text { surface is sputtered } \\
\text { in vacuum system } \\
\text { prior to silver } \\
\text { coating }\end{array}$ & 22 \\
\hline $\begin{array}{l}\text { Naimon } \\
\text { etal. }\end{array}$ & $\begin{array}{l}\text { On lapping } \\
\text { machine with } \\
3-\mu \text { m alumina } \\
\text { with a light } \\
\text { oil } \\
\text { vehicle }\end{array}$ & & $\begin{array}{l}\text { Detergent wash and } \\
\text { alcohol rinse }\end{array}$ & & $\begin{array}{l}\text { Proved flat to } \\
\text { one light band }\end{array}$ & $\begin{array}{l}\text { Procedure for } \\
\text { preparing surfaces } \\
\text { for silver } \\
\text { deposition } \\
\text { procedures; also } \\
\text { surface is sputtered } \\
\text { in vacuum system } \\
\text { prior to silver } \\
\text { coating }\end{array}$ & 23 \\
\hline
\end{tabular}


The application of a thin film of mercury over a silver- coated beryllium was found to provide reliable, reproducible bond strengths. The mercury does not increase the maximum strength; rather, it reduces the scatter in bond strengths otherwise obtained due to contamination and roughness of the silver coating. A thin layer of mercury (e. g., $0.5 \mu \mathrm{m}$ thick) is obtained by electrode deposition using a cyanide electroplating solution. The mercury then rapidly migrates into the silver forming a two-phase structure. The silver is thus strengthened by solid-solution hardening and by precipitation hardening of the Ag-rich Hg precipitates. The mercury- activated silver allows reliable, reproducible, high-strength joints to be made between silver-coated parts that have been in long-time storage. ${ }^{16}$

A summary of various surface preparations for bonding beryllium reported by a number of investigators is given in Table X-3-4. ${ }^{16}$ All the procedures involve first obtaining a flat surface. Both solvents and detergents have been used. Detergent-cleaned-beryllium surfaces were shown to have less contamination than solvent-cleaned surfaces. Corrosion pits can form if the beryllium is galvanically coupled to a more noble material such as stainless steel especially if chlorine ions are present in the cleaning solution. Tap water can also be a source of pitting. Corrosion pits have been identified as initiation sites of bond failures. It may be noted in the table, when evaluating different acid solutions to remove heavy oxide layers, the $10 \% \mathrm{H}_{2} \mathrm{SO}_{4}$ solution proved to be best. Chemical etching that resulted in a matte surface was not conducive to achieving satisfactory bonds. Cleaning by ion-sputtering facilitated achieving direct beryllium bonding at temperatures as low as $200^{\circ} \mathrm{C}$. A cleaning procedure that was reported involves a solution of $5 \% \mathrm{HF}-45 \%$ $\mathrm{HNO}_{3}$ in water. ${ }^{12}$

Grit blasting with chilled-cast-iron grit followed by cleaning with dilute nitric acid to remove embedded grit was found to be superior to other methods when used prior to forming joints by gas-pressure bonding. Smooth mechanically prepared surfaces were found to recrystallize near $700^{\circ} \mathrm{C}$ prior to reaching the required bonding temperature and pressure. With grit blasting, the numerous asperations formed by the blasting resulted in additional deformation that caused recrystallization to occur following the initial recrystallization. The two recrystallizations were accompanied by grain growth across 20 to $50 \%$ of the interface. ${ }^{19}$ This cleaning procedure would not be applicable when bonding under low pressures where surfaces must be flat.

\section{$\underline{\mathrm{X}-3-5-\text { Joint Design }}$}

The basic joints for diffusion bonding are butt and lap joints. Illustrations of various lap joints are shown in Fig. X-3-3 An important consideration in designing a joint of dissimilar metals is the difference in their coefficient of thermal expansion (CTE). For example, a bar having a higher CTE than a plate to which it will be bonded should preferably be joined using an insert-lap joint instead of a conventional tee joint. The two joints are illustrated in Fig X-3-4. Several examples of tee joints are shown in Fig X-3-5. A tee joint is actually a form of a butt joint. Bond strengths can be increased by reinforcements as illustrated in Figs. X-3-3 and X-3-5 or by increasing the interface area as shown in Fig. X-3-6. Joining of light and heavy sections should generally be designed with reinforcements. 


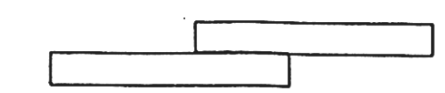

a. SINGLE LAP JOINT

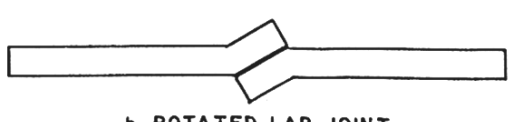

b. ROTATED LAP JOINT

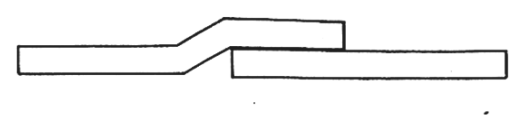

c. SINGLE JOGGLED LAP JOINT

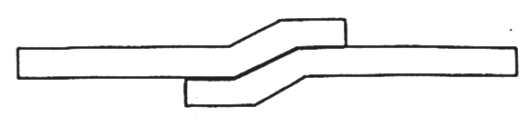

d. DOUBLE JOGGLED LAP JOINT

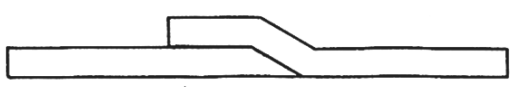

. SCARF - JOGGLED LAP JOINT

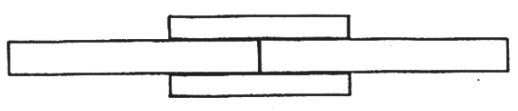

f. BUTT AND LAP JOINT

Fig. X-3-3 Variations of lap joints for diffusion. ${ }^{19}$
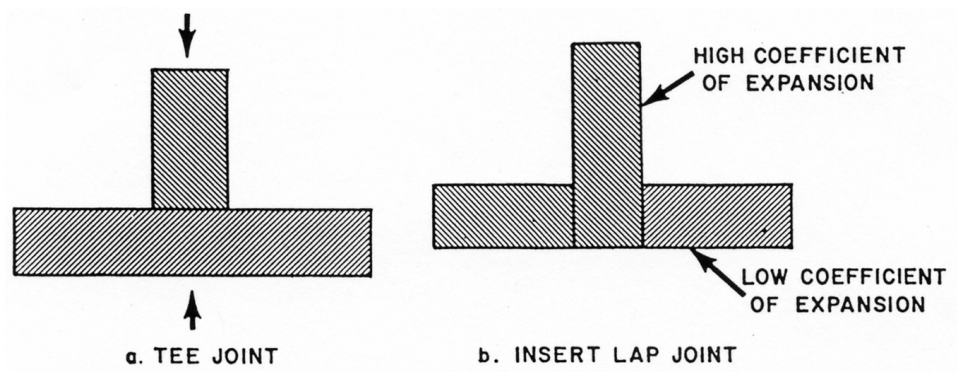

b. INSERT LAP JOINT

Fig. X-3-4 Joint designs in diffusion bonding: a) conventional tee joint; b) modified tee joint to minimize residual stress due to differential coefficient of thermal expansion. ${ }^{19}$

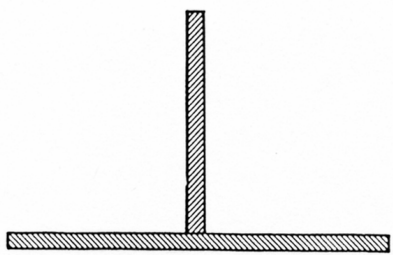

a. TEE JOINT

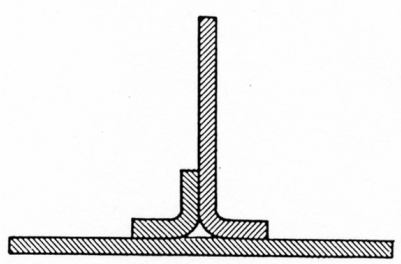

c. SINGLE-REINFORCED, LAPPED - TEE JOINT

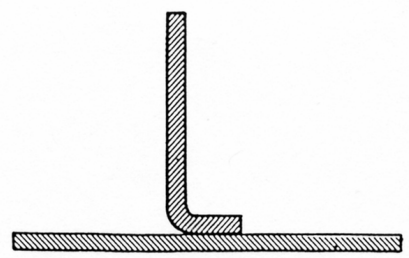

b. LAPPED - TEE JOINT

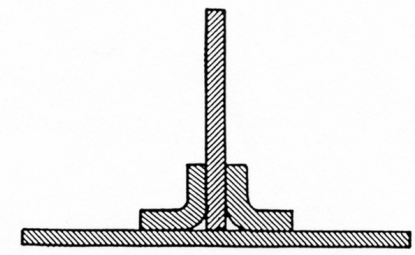

d. DOUBLE-REINFORCED TEE JOINT

Fig. X-3-5 Variations of tee joints for diffusion. ${ }^{19}$

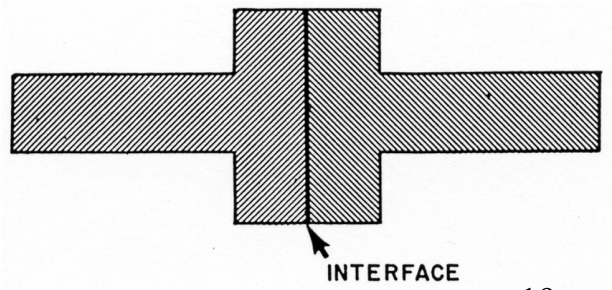

Fig.X-3-6 Butt joint strengthened by increased joint area. 19 


\section{$\underline{\text { X-3-6-Solid-State-Bonding Equipment }}$}

Typical heating sources for solid-state bonding include radiation, induction, and self-resistance heating. Loads can be applied by hydraulic or mechanical means and by differential thermal expansion, usually with reference to a fixed jig. The disadvantage of loading by differential expansion is that control of the load is limited in that it is temperature dependent. Loads greater and more controllable than those obtained by thermal expansion may be required to optimize joint strength. The equipment used must maintain protection of the bonding surfaces from contamination from the ambient atmosphere. Solid-state bonding, however, has been obtained between silver surfaces at the lower bonding temperatures without atmospheric protection. Deformation bonding of sheet might possibly be done by roll bonding. Although the bonding operation can readily be performed by adapting to existing facilities such as a vacuum hot press, a mechanical-testing system or perhaps additions to a furnace, for production purposes it is best to use equipment designed for a specific bonding operation.

Press welding, which consists of applying pressure to the parts placed between two platens or shaped dies held in a press, usually involves relatively simple procedures and equipment. The method is well suited for joining flat parts, parts having parallel opposite faces, sandwich composites, and butted rods or tubes. The latter two may have to be performed within a sleeve to prevent lateral deformation. An internal mandrel may also be used for the tube. The method offers the ability for good control and precise measurement of the loading.

Differential-thermal expansion (DTE) bonding utilizes the stress developed due to the DTE between the pieces to be joined and the supporting fixture or between the pieces themselves. The equipment requirement is relatively inexpensive. Precise measurement and control of the bonding pressure are difficult.

In the gas-pressure-bonding process, the components to be joined are fabricated or machined to final size and cleaned. The assembled components are then either placed in a flexible, expendable container, which is then sealed or edge welded to produce a pressure-tight evacuated enclosure. Residual gases should be evacuated; otherwise, they may become entrapped in the weld interfaces and interfere with the bonding. The assembled components are then heated to the bonding temperature in an autoclave containing an inert gas under high pressure, which is transmitted uniformly to the components, forcing all the mating surfaces into intimate contact. Maximum allowable operating pressures are usually used to lower the temperature and/or time in order to minimize grain growth and excessive diffusion. Because of the isostatic pressure, the process is especially suited for joining of brittle materials with decreased danger of cracking.

Roll bonding, which does not depend on diffusion, requires some minimum amount of deformation, of the order of $40 \%$ or greater, depending on the material, surface preparation, rolling conditions, and temperature. Residual stresses, developed when bonding materials having significant differences in the coefficient of thermal expansion, could be a limiting factor in using this process. Studies on roll bonding of aluminum showed that the shear strength of the Al-Al bond increased with increased deformation as well as by roughening (by wire brushing) and increased cleaning of the surfaces. ${ }^{19}$ A threshold deformation of $40 \%$ at ambient temperature was reported in order to obtain a measurable strength for degreased and wire-brushed surfaces 
compared to over $50 \%$ for an as-machined surface. Bonding was not obtained at $77 \%$ deformation for aluminum electropolished surfaces. The threshold value was reduced with increasing temperature, from 40 to $5 \%$ on increasing the temperature from ambient to $600^{\circ} \mathrm{C}$. By baking out, machining, and rolling in vacuum (within five seconds after rolling), the deformation threshold for aluminum at ambient temperature was reduced from 40 to $10 \%$. As with aluminum, the high reactivity of beryllium with oxygen would require a limited exposure time of the surface between cleaning and rolling.

\section{$\underline{\mathrm{X}-3-7-\text { Evaluation of Bond Strengths }}$}

Defective diffusion bonds may be the result of:

- total or partial lack of bonding at an interface

- failure of adherence of intermediate layers to the beryllium

- formation of brittle intermetallics at the interface under certain conditions

- crack initiation (notch effect) at edge of bond interface due to deformation while bonding

- crack initiation at etch pits formed during cleaning prior to bonding

- lack of cleanliness, lack of flatness, and/or lack of smoothness of bonding surfaces

Because of the intimate contact of bonded surfaces, the integrity of a bond cannot readily be ascertained by conventional non-destructive evaluation methods such as radiography or ultrasonics. High-sensitivity ultrasonics has shown to be promising under favorable conditions. Acoustic-emission monitoring during proof testing also shows promise for assessing the integrity of a bond. ${ }^{16}$

\section{$\underline{\mathrm{X}-3-8 \text {-Bonding of Beryllium with other Materials }}$}

A number of investigations have been reported on bonding of beryllium with other metals. In many cases where intermediate layers were used, they consisted of materials other than silver. In one study, S-65C beryllium was bonded to dispersion-strengthened copper (DSCu) either directly or by using an interlayer insert of a $50-\mu$ m-thick $\mathrm{Be}-\mathrm{Cu}(\mathrm{Cu}-1.8 \% \mathrm{Be})$ foil. ${ }^{20}$ The bonding was achieved by vacuum hot-isostatic pressure at a pressure of $50 \mathrm{MPa}$. Bonding temperatures ranged from 600 to $850^{\circ} \mathrm{C}$ for one hour except at $700^{\circ} \mathrm{C}$ where tests ranged from one to six hours. Shearstrength results as a function of bonding temperature are shown in Fig. X-3-7. A slight drop in strength occurs with increasing bonding temperature. Consistent with this trend, an initial rise in strength followed by a drop was obtained with increasing bonding time at $700^{\circ} \mathrm{C}$. Scanningelectron and X-ray-diffraction analyses of the joints revealed growth of diffusion layers with increasing temperature or time. Fig. X-3-8 shows the diffusion-layer thickness as a function of temperature. Similar growth behavior was obtained with increasing time at $700^{\circ} \mathrm{C}$. In the absence of the insert, $\mathrm{a} \mathrm{Be}_{2} \mathrm{Cu}(\delta)$ phase formed on the $\mathrm{Be}$ side and $\mathrm{Cu}+\mathrm{BeCu}(\gamma)$ phase formed on the $\mathrm{DSCu}$ side. These same phases were obtained at the $\mathrm{Be}$ and $\mathrm{DSCu}$ sides when using the $\mathrm{Be}-\mathrm{Cu}$ foil. The authors conclude that the shear strength is affected mainly by the growth of the $\mathrm{Be}_{2} \mathrm{Cu}$ phase at the beryllium interface and that the presence or absence of an insert is unimportant. 


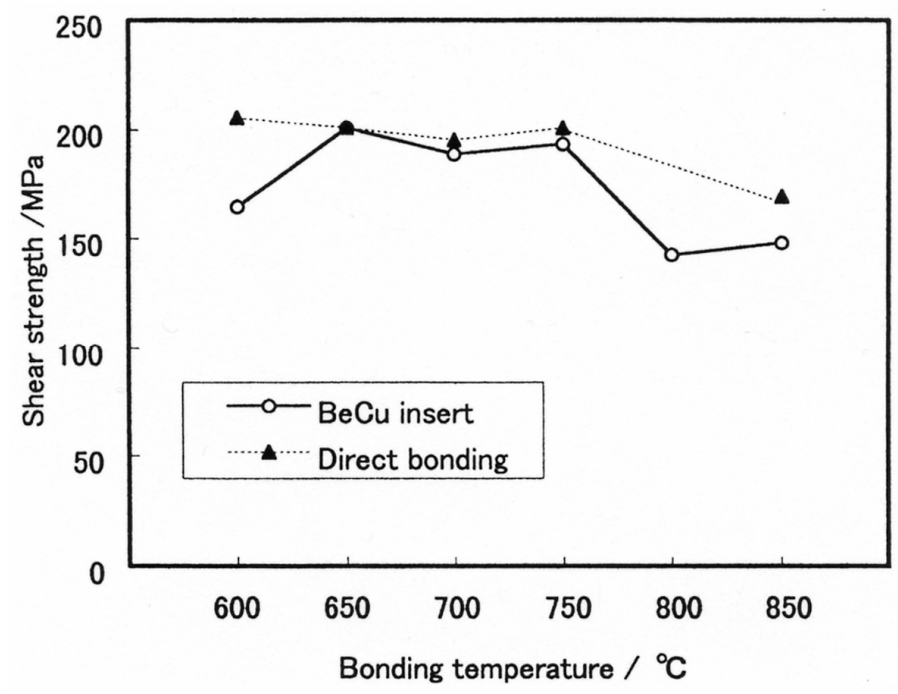

Fig. X-3-7 Dependence of shear strength on bonding temperature for S-65C beryllium bonded to dispersion-strengthened copper 20

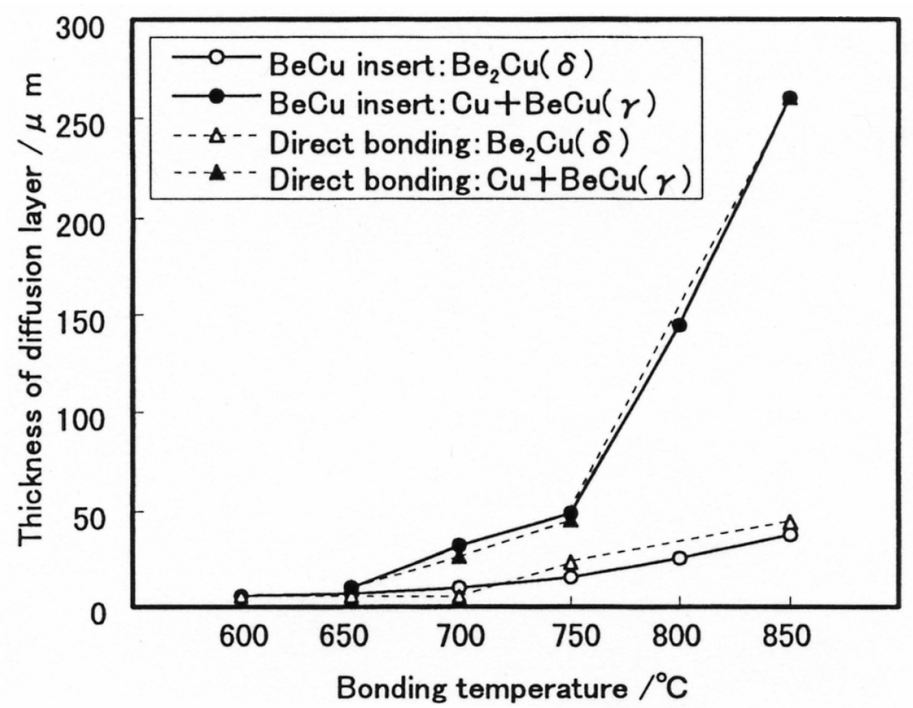

Fig. X-3-8 Dependence of diffusion-layer thickness on bonding temperature for S-65C beryllium bonded to dispersion-strengthened copper 20

Preliminary results obtained in evaluating the potential use of $\mathrm{Be}-\mathrm{Cu}$ and $\mathrm{Be}-\mathrm{CuCrZr}$ bonds for Be-Cu heat-sink structures are listed in Tables X-3-5 and X-3-6 for tensile and shear specimens, respectively. ${ }^{21}$ Brazing and roll-bonding results are included with the solid-state-diffusion results. A silver-based brazing alloy was used for brazing, performed in vacuum at $760^{\circ} \mathrm{C}$. No intermediate layer was used for diffusion or roll bonding. The diffusion bonds were made in vacuum at $720^{\circ} \mathrm{C}$ under a pressure that corresponded to the initiation of plastic deformation of the copper. 


\begin{tabular}{|l|l|l|l|l|l|}
\hline \multicolumn{3}{|l|}{ Table X-3-5 Results of Tensile Testing Be-Cu and Be-CuCrZr Bonded Samples. } \\
\hline $\begin{array}{l}\text { Bonded } \\
\text { Materials }\end{array}$ & $\begin{array}{l}\text { Joining } \\
\text { method }\end{array}$ & $\begin{array}{l}\text { Test temp } \\
{ }^{\mathrm{C}}\end{array}$ & $\begin{array}{l}\text { Strength } \\
\mathrm{MPa}\end{array}$ & Failure zone & Comments \\
\hline $\mathrm{Be}-\mathrm{Cu}$ & Brazing & 20 & 81 & Through brazing alloy & Brittle fracture \\
\hline $\mathrm{Be}-\mathrm{Cu}$ & Brazing & 20 & 103 & Through brazing alloy & Brittle fracture \\
\hline $\mathrm{Be}-\mathrm{Cu}$ & Brazing & 350 & 125 & Through brazing alloy & Mainly brittle \\
\hline $\mathrm{Be}-\mathrm{Cu}$ & Brazing & 350 & 212 & Through $\mathrm{Cu}$ & Ductile failure of $\mathrm{Cu}$ \\
\hline $\mathrm{Be}-\mathrm{CuCrZr}$ & Diff. bonding & 20 & 188 & Through $\mathrm{Be}$ & Brittle fracture \\
\hline $\mathrm{Be}-\mathrm{CuCrZr}$ & Diff. bonding & 20 & 103 & Through Be & Brittle fracture \\
\hline $\mathrm{Be}-\mathrm{CuCrZr}$ & Diff. bonding & 350 & 191 & Through Be & Brittle fracture \\
\hline $\mathrm{Be}-\mathrm{Cu}$ & Diff. bonding & 20 & & & failed after machining \\
\hline $\mathrm{Be}-\mathrm{Cu}$ & Diff. bonding & 20 & & & failed after machining \\
\hline $\mathrm{Be}-\mathrm{Cu}$ & Diff. bonding & 20 & 21 & Through Be-Cu bond line & Brittle fracture \\
\hline $\mathrm{Be}-\mathrm{Cu}$ & Roll bonding & 20 & 53 & Through Be-Cu bond line & Brittle fracture \\
\hline $\mathrm{Be}-\mathrm{Cu}$ & Roll bonding & 20 & 70 & Through Be-Cu bond line & Brittle fracture \\
\hline
\end{tabular}

\begin{tabular}{|l|l|l|l|l|l|}
\hline \multicolumn{3}{|l|}{ Table X-3-6 Results of Shear Testing Be-Cu and Be-CuCrZr Bonded Samples. } \\
\hline $\begin{array}{l}\text { Bonded } \\
\text { Materials }\end{array}$ & $\begin{array}{l}\text { Joining } \\
\text { method }\end{array}$ & $\begin{array}{l}\text { Test temp } \\
{ }^{\mathrm{C}}\end{array}$ & $\begin{array}{l}\text { Shear } \\
\text { Strength } \\
\mathrm{MPa}\end{array}$ & Failure zone & Comments \\
\hline $\mathrm{Be}-\mathrm{Cu}$ & Brazing & 20 & 72 & Through brazing alloy & Brittle fracture \\
\hline $\mathrm{Be}-\mathrm{Cu}$ & Brazing & 20 & 123 & Through brazing alloy & Brittle fracture \\
\hline $\mathrm{Be}-\mathrm{Cu}$ & Brazing & 350 & 126 & Through $\mathrm{Cu}$ & Ductile failure of $\mathrm{Cu}$ \\
\hline $\mathrm{Be}-\mathrm{Cu}$ & Brazing & 350 & 213 & Through $\mathrm{Cu}$ & Ductile failure of $\mathrm{Cu}$ \\
\hline $\mathrm{Be}-\mathrm{CuCrZr}$ & Diff. bonding & 20 & 43 & Through $\mathrm{Be}$ & Crack in $\mathrm{Be}$ \\
\hline $\mathrm{Be}-\mathrm{CuCrZr}$ & Diff. bonding & 20 & 103 & Through $\mathrm{Be}$ & Crack in $\mathrm{Be}$ \\
\hline $\mathrm{Be}-\mathrm{CuCrZr}$ & Diff. bonding & 350 & 107 & Through $\mathrm{Be} / \mathrm{Cu}$ bond line & Brittle fracture \\
\hline $\mathrm{Be}-\mathrm{Cu}$ & Diff. bonding & 20 & 82 & Through $\mathrm{Be} / \mathrm{Cu}$ bond line & failed after machining \\
\hline $\mathrm{Be}-\mathrm{Cu}$ & Diff. bonding & 20 & 75 & Through $\mathrm{Be} / \mathrm{Cu}$ bond line & failed after machining \\
\hline $\mathrm{Be}-\mathrm{Cu}$ & Diff. bonding & 20 & 152 & Through $\mathrm{Be}-\mathrm{Cu}$ bond line & Brittle fracture \\
\hline $\mathrm{Be}-\mathrm{Cu}$ & Roll bonding & 20 & 123 & Through intermetallic & Brittle fracture \\
\hline $\mathrm{Be}-\mathrm{Cu}$ & Roll bonding & 20 & 141 & Through $\mathrm{Cu}$ & Ductile failure of $\mathrm{Cu}$ \\
\hline
\end{tabular}

It appears that that direct bonding of $\mathrm{Be}$ to $\mathrm{Cu}$ would not be feasible due to the formation of brittle $\mathrm{Be}-\mathrm{Cu}$ intermetallics. In addition, the high mismatch in the coefficient of thermal expansion results in corresponding high stresses. Interlayers should be used to both act as a diffusion barrier and to relieve these thermal residual stresses by plastic deformation.

An evaluation was reported on the use of $50-\mu \mathrm{m}$-thick titanium foil as an intermediate layer in diffusion bonding S-65C beryllium to Glidcop (99.5Cu-0.25Al in wt.\%). ${ }^{22}$ The $\mathrm{Cu}$ and Be pieces each measured $10 \times 10 \times 5 \mathrm{~mm}$. Surfaces were chemically cleaned. The bonding was performed by hot isostatic pressing. Two different bonding cycles were evaluated: 1) heat to $850^{\circ} \mathrm{C}$ and 100 $\mathrm{MPa}$ in three hours, hold for two hours, and cool to room temperature and $0.1 \mathrm{MPa}$ in five hours; 2) heat to $850^{\circ} \mathrm{C}$ and $120 \mathrm{MPa}$ in three hours, hold for two hours, cool to $400^{\circ} \mathrm{C}$ and $3 \mathrm{MPa}$ in two hours, hold for two hours, and cool to room temperature in one to two hours. Room-temperature 
tests gave ultimate shear strengths of about 30 and108 $\mathrm{MPa}$ for bonds formed by procedures 1) and 2), respectively. Failure occurred at the interface between Be and the Ti-Be intermetallics $\left(\mathrm{TiBe}_{12}\right.$ and $\left.\mathrm{TiBe}_{2}\right)$. Other phases that formed across the titanium foil were $\mathrm{Ti}_{2} \mathrm{Cu}, \mathrm{TiCu}, \mathrm{Ti}_{2} \mathrm{Cu}_{3}$ $+\mathrm{Ti}_{3} \mathrm{Cu}_{4}$ (cracks were associated with these two latter phases), and $\mathrm{TiCu}_{4}$.

The joining of hot-pressed beryllium with 316L stainless steel both directly and with interlayers of copper and copper with nickel was evaluated. ${ }^{23}$ The beryllium contained 6100 ppm BeO, 270 ppm $\mathrm{Be}_{2} \mathrm{C}$, and $800 \mathrm{ppm} \mathrm{Fe}$. Bonding was achieved by hot isostatic pressing at $65 \mathrm{MPa}$ for two hours at $930^{\circ} \mathrm{C}$ in argon. Evaluations of the joints were made using light microscopy, scanning Auger microscopy, nanoindenter-hardness measurements, and tensile tests. Direct bonding led to the appearance of cracks due to the formation of brittle Be-Fe intermetallics; a tensile strength of less than $10 \mathrm{MPa}$ was achieved. Using a copper interlayer prevented the diffusion of iron into the beryllium. However, beryllium was able to diffuse through the copper into the stainless steel (SS) and led to cracking at the $\mathrm{Cu}-\mathrm{SS}$ interface. No cracks formed for the $\mathrm{Be}-\mathrm{Cu}-\mathrm{Ni}-\mathrm{SS}$ bond, which achieved a tensile strength of $50 \mathrm{MPa}$. The nickel layer impeded the diffusion of beryllium into the SS, thus avoiding the formation of brittle Be-Fe intermetalllics. The diffusion widths ranged between 350 and $400 \mu \mathrm{m}$. Due to the intermetallics and solid-solution hardening, hardness values increased by as much as a factor of four across the diffusion regions relative to that of beryllium. Interlayer thicknesses were not given.

In forming a joint between beryllium and another metal, the difference in the thermal-expansion coefficient (TEC) between the two metals can result in excessive residual stresses. To minimize this problem, iron or nickel interlayers ( 0.9 to1.3 mm thick) were used in solid-state bonding of Be to $\mathrm{Cu}-0.65 \mathrm{Cr}-0.1 \mathrm{Zr}$ (wt.\%). ${ }^{24}$ In addition, an interlayer of $130-\mu \mathrm{m}$-thick silver foil was used as a reaction barrier to limit the formation of brittle beryllium intermetallics. Silver does not form any intermetallics below $760^{\circ} \mathrm{C}$. Bonding of beryllium to a $\mathrm{V}-5 \mathrm{Cr}-5 \mathrm{Ti}$ (wt.\%) alloy using $\mathrm{Ag}$ as a reaction barrier was also evaluated. Instead of $\mathrm{Fe}$ or $\mathrm{Ni}$, an $\mathrm{Al}-\mathrm{Be}$ interlayer (1.25 mm thick) was used for the $\mathrm{Be}-\mathrm{Cu}$ bonding. The Al-Be layer was plasma sprayed on to the $\mathrm{Be}$, attempting to obtain a gradation from zero to $40 \% \mathrm{Al}$. The TECs as a function of temperature for these materials are shown in Fig. X-3-9. The TECs for both Fe and Ni are close to that of Be over most of the temperature range, whereas the $\mathrm{Cu}$ and Be curves are distinctly different from each other.

The different materials were cut into $25-\mathrm{mm}$ discs, degreased, cleaned (which included first a five-minute etch in a $30 \mathrm{HNO}_{3}-10 \mathrm{Hf}-60 \mathrm{H}_{2} \mathrm{O}$ solution), stacked for bonding, and inserted into stainless-steel cans that were then evacuated. The samples were then hot isostatically pressed for 0.5 hours at $762{ }^{\circ} \mathrm{C}$ at a pressure of $110 \mathrm{MPa}$. Some samples were sectioned for light microscopy and scanning-electron microscopy; others were machined into compression-shear samples. The $\mathrm{Cu}-\mathrm{Ni}-\mathrm{Ag}-\mathrm{Be}$ and $\mathrm{Cu}-\mathrm{Ag}-\mathrm{AlBe}-\mathrm{Be}$ samples delaminated during machining, leaving only the $\mathrm{Cu}-$ $\mathrm{Fe}-\mathrm{Ag}-\mathrm{Be}$ and $\mathrm{V}-\mathrm{Ag}-\mathrm{Be}$ to be tested. 


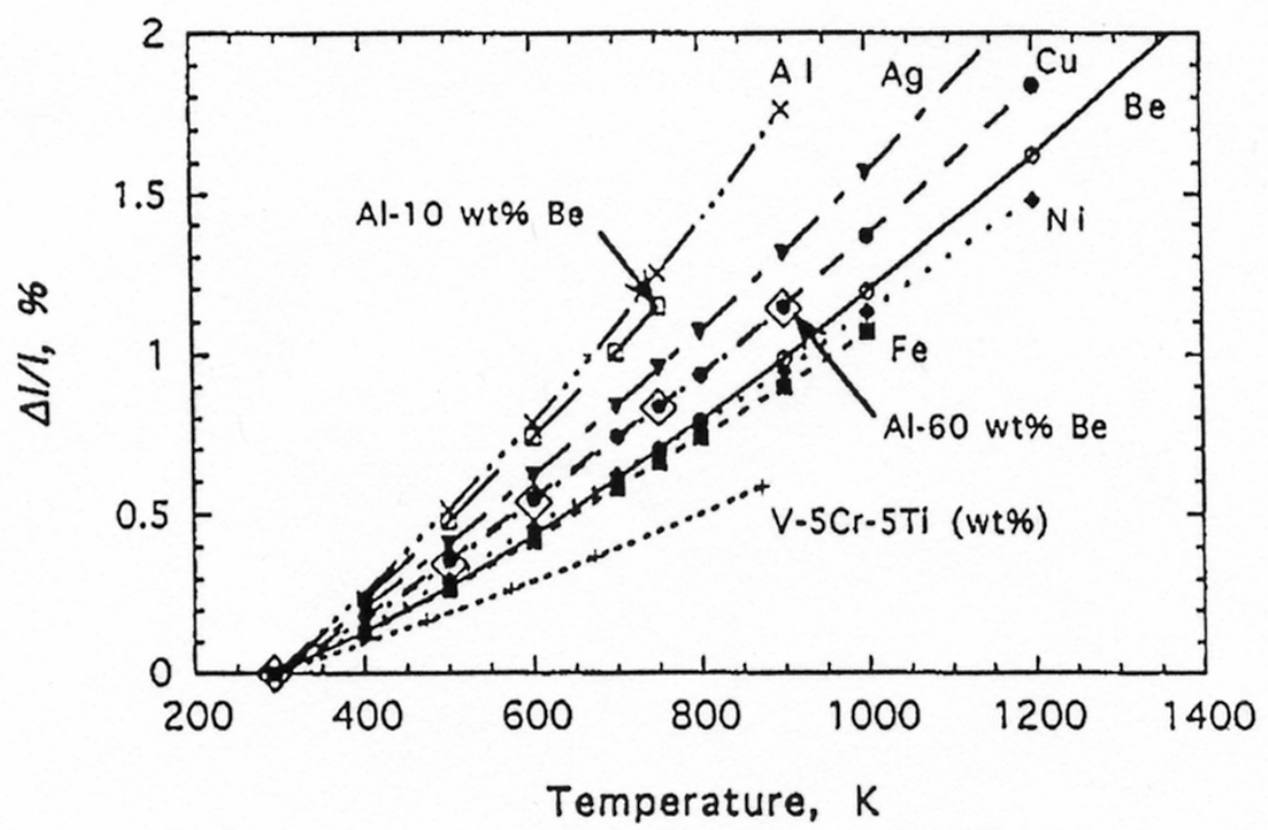

Fig. X-3-9 Thermal Expansion of beryllium compared to several possible inserts. ${ }^{24}$

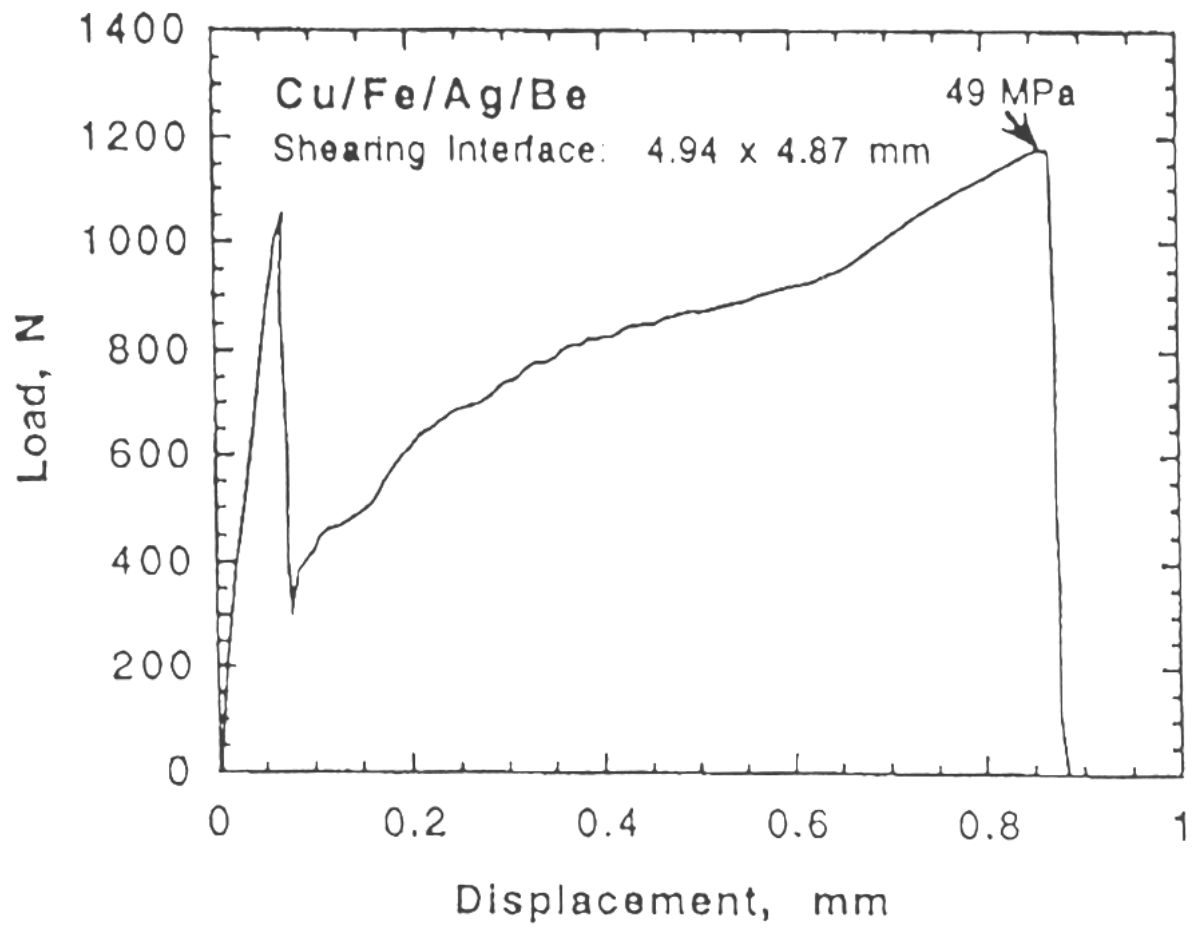

Fig. X-3-10 Load-displacement for a simple shear specimen of copper bonded to beryllium with interlayers of $\mathrm{Fe}$ and $\mathrm{Ag}$ as $\mathrm{Cu}-\mathrm{Fe}-\mathrm{Ag}-\mathrm{Be}{ }^{24}$ 
The load in the shear tests, following a small plastic strain (crosshead displacement of 10 to 20 $\mu \mathrm{m})$, typically reached a maximum value followed by a sharp drop. In most cases the load increased again during further deformation. A typical example is shown in Fig. X-3-10. Shear strengths reported were 49 and $55 \mathrm{MPa}$ for the $\mathrm{Cu}-\mathrm{Fe}-\mathrm{Ag}-\mathrm{Be}$ samples and 77 and $78 \mathrm{MPa}$ for the V-Ag-Be samples.

Interaction at the $\mathrm{Ag}-\mathrm{Be}$ interface in the $\mathrm{Cu}-\mathrm{Ni}-\mathrm{Ag}-\mathrm{Be}-$ and $\mathrm{Cu}-\mathrm{Fe}-\mathrm{Ag}-\mathrm{Be}$ samples were not evident even though the hot isostatic-pressing temperature was very close to the temperature where $\mathrm{AgBe}_{2}$ forms. The apparent lack of such interaction is consistent with the low mutual solid solubility of silver and beryllium (see Fig. X-3-2). Failures usually occurred at the Ag-Be interface. The authors conclude that achieving a minimum mismatch in the thermal coefficient of

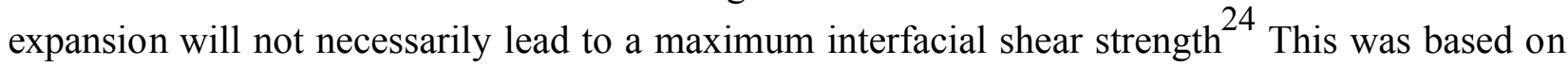
their results showing that the $\mathrm{V}-\mathrm{Ag}-\mathrm{Be}$ samples showed a higher shear stress than did the $\mathrm{Cu}-\mathrm{Fe}-$ Ag-Be samples, although the CTE mismatch between the $\mathrm{V}$ alloy and $\mathrm{Be}$ is much greater than it is between iron and $\mathrm{Be}$.

\section{X-3-9-Flash Welding}

Flash welding is a form of solid-state bonding. It is a resistance/forge-welding process in which the items to be welded are securely clamped to electric-current dies, heated by the current, and upset. It is a rapid, economical process that can produce a uniform, high-quality weld; it is used primarily for production quantities. With beryllium (and other toxic metals) flash welding should only be used under stringent precautionary measures to prevent contamination of equipment, air, surroundings, and personnel by flash particles and dust.

\section{X-4-Soldering}

Typical applications of soldering in beryllium include those requiring high electrical conductivity with low stresses, applications requiring a mass-spectrometer leak-tight joint with low stresses, low-temperature applications where nonmetallic materials are not permissible, and high-voltage applications. ${ }^{14}$ Typically, soldering of beryllium has been performed using indium-based solders, e. g., $90 \%$ In-10\% Ag. Soldering beryllium to beryllium and beryllium to copper have been successfully accomplished. Minor defects or discontinuities in a brazed joint can be repaired by soldering. By first plating beryllium with copper and then nickel, beryllium surfaces can be joined to each other using silver solder. ${ }^{12}$ 


\section{References}

1. CRC Handbook of Chemistry and Physics, Editor-in-Chief, David D. Lide, Publ., The Chemical Rubber Company Press, New York, NY, pp.,8/21-8/31, 2000-2001.

2. J. Vaccarri, Welding Beryllium Takes Special Care, American Machinist, vol 135, (4), pp. 46-48, April, 1991.

3. M. A. Hill etal., Beryllium Weldability, in Weldability of Materials, Detroit, MI, Pub. ASM, pp. 331-339, October, 1990.

4. Metals Handbook, Ninth Ed., vol.6, Welding, Brazing, and Soldering, Publ. American Society of Metals, Metals Park, OH, p. 29, 1986.

5. P. Banaim, etal., Joining of Beryllium by Braze Welding Technique: Preliminary Results, JAERI Conf 98-01 in Proc of 3rd IEA International Workshop on Beryllium Technology for Fusion, Milo City, Japan, Oct. 22-24, 1997, pp. 93-101, 1998.

6. Metals Handbook, Ninth Ed., vol.6, Welding, Brazing, and Soldering, Publ. American Society of Metals, Metals Park, OH, p. 1052, 1986.

7. Metals Handbook, Ninth Ed., vol.6, Welding, Brazing, and Soldering, Publ. American Society of Metals, Metals Park, OH, pp. 461-462, 1986.

8. J. D. Cotton and R. D. Field, Microstructural Features of Cracking in Autogenous Beryllium Weldments, Metall and Mater Trans A, vol. 28A, pp. 673-680, March, 1997.

9. PVD Aluminum on Beryllium, Internal Communication from Jesse West to Bob Juntz, LLNL January 14,1986.

10. G. K. Hicken and W. B. Sample, Joining Beryllium by an Electron Beam Braze Welding Technique, Welding Jl., vol. 46 (12), pp. 541-S to 550-S, 1967.

11. R. B. Barker, Beryllium Braze-Welding Porosity and Arc-Parameter Studies, Internal Document, Dow Chemical Company, RFP-287 (undated).

12. L. A. Jacobson, Joining Methods for Beryllium--A Survey, UCID-20750, May 16, 1986.

13. Brazing Handbook, Fourth Ed., Publ. American Welding Society, Miami, Florida, 1991.

14. L. A. Grant, Joining II: Brazing and Soldering, in Beryllium Science and Technology, vol. 2, (13), Eds., D. R. Floyd and J. N. Lowe, Plenum Publ. Corp., pp 249-273, 1979.

15. C. W. Marschall, Testing of Beryllium Brazed Joints at Temperatures up to $1200 \mathrm{~F}$. Light Metals, in Current Awareness Bulletin, Issue no. 201, pp. 1-3, Publ. Ceramic Information Center, 1990.

16. D. L. Olson and A. L. Liby, Joining 11l: Diffusion Bonding, Beryllium Science and Technology, vol. 2 (14), Eds. D. R. Floyd and J. N. Lowe, Plenum Publishing Corp., pp. 275296, 1979

17. J. L. Knowles and T. H. Hazlett, High-Strength, Low-Temperature Bonding of Beryllium and other Metals, UCRL-72342 Preprint, February 24, 1970.

18. Binary Alloy Phase Diagrams, Second Edition, vol. 1, Publ., ASM International, Metals Park, OH, p. 14, 1990.

19. D. Hauser et al, Fundamentals of Solid State Welding and their Application to Beryllium, Aluminum, and Stainless Steel, RSIC-437, Battelle Memorial Institute, Columbus, Ohio, July 15, 1965. 
20. T. Makino and T. Iwadachi, Interface Formation and Strength of Be/DSCu Diffusion Bonding, J. Nuclear Materials, vol. 258-263, pp. 313-317, 1998.

21. A. A. Gervash etal., Metallographoc Analysis and Strength Investigation of Different Be-Cu Joints in the Temperature Range RT-350 C, J. of Nuclear Materials, vol. 233-237, Pt A, pp. 626-631, October, 1996.

22. F. Saint-Antonin etal., Development and Characterization of Be/Glidcop Joints obtained by Hot Isostatic Pressing for High Temperature Working Conditions, J. of Nuclear Materials, vol 258-263, Pt A, pp 1973-1978, October, 1998.

23. Peng-cheng Zhang etal., Distribution of the Composition and Micromechanical Properties of Be/316L Stainless Steel following Diffusion Bonding, Surface Interface Analysis, vol. 32, pp 88-90, 2001.

24. J. H. Schneibel etal., Solid State Bonding of Beryllium to Copper and Vanadium using Transition Layers, J. of Nuclear Materials, vol. 250, (2-5), pp. 216-222, December, 1997. 